\title{
ARTICLE Central role of myeloid MCPIP1 in protecting against LPS- induced inflammation and lung injury
}

Yong $\mathrm{Li}^{1,2,7}$, Xuan Huang ${ }^{1,2,7}$, Shengping Huang ${ }^{1,7}$, Hui He ${ }^{1}$, Tianhua Lei ${ }^{1}$, Fatma Saaoud ${ }^{3}$, Xiao-Qiang Yu ${ }^{4}$, Ari Melnick ${ }^{5}$, Anil Kumar ${ }^{6}$, Christopher J Papasian', Daping Fan ${ }^{3}$ and Mingui Fu

Although systemic inflammatory responses attributable to infection may lead to significant lung injury, the precise molecular mechanisms leading to lung damage are poorly understood and therapeutic options remain limited. Here, we show that myeloid monocyte chemotactic protein-inducible protein 1 (MCPIP1) plays a central role in protecting against LPS-induced inflammation and lung injury. Myeloid-specific MCPIP1 knockout mice developed spontaneous inflammatory syndromes, but at a late age compared to global MCPIP1 knockout mice. Moreover, mice with a myeloid-specific deletion of MCPIP1 were extremely sensitive to LPS-induced lung injury due to overproduction of proinflammatory cytokines and chemokines. We identified C/EBP $\beta$ and C/EBPS, two critical transcriptional factors that drive cytokine production and lung injury, as targets of MCPIP1 RNase. LPS administration caused MCPIP1 protein degradation in the lungs. Pharmacological inhibition of MALT1, a paracaspase that cleaves MCPIP1, by MI-2 selectively increased the MCPIP1 protein levels in macrophages and in the lungs. Meanwhile, administration of MI-2 protected mice from LPS-induced inflammation, lung injury and death. Collectively, these results indicate that myeloid MCPIP1 is central in controlling LPS-induced inflammation and lung injury. Pharmacological inhibition of MALT1 protease activity may be a good strategy to treat inflammatory diseases by enhancing MCPIP1 expression in myeloid cells.

Signal Transduction and Targeted Therapy (2017) 2, e17066; doi:10.1038/sigtrans.2017.66; published online 8 December 2017

\section{INTRODUCTION}

The primary benefit derived from the host inflammatory response to infection is the potential eradication or containment of invading microbes. Significant cell damage and destruction are other consequences of the inflammatory response to infection, and when these inflammatory responses become systemic (that is, sepsis), multi-organ failure and death are common outcomes. ${ }^{1}$ Acute lung injury, a syndrome characterized by pulmonary inflammation and vascular hyperpermeability, is a particularly common finding in sepsis, substantially contributing to mortality. ${ }^{2,3}$ The basic pathological mechanism of sepsis-induced lung injury involves the destruction of pulmonary capillaries and alveolar epithelia. ${ }^{4-8}$

The host inflammatory response is mediated by cytokines, and their production is precisely regulated to permit rapid, robust responses to invading microbes, along with attenuation of those responses once the threat has been contained. ${ }^{9,10}$ Lipopolysaccharide (LPS) is a component of the outer membrane of Gramnegative bacteria; it is among the most potent triggers of host inflammatory responses, and LPS-induced cytokine production is regulated at both the transcriptional and post-transcriptional levels. Transcription of cytokine genes is controlled by the following three transcription factors: NF-KB, C/EBPS and ATF-3. The activation of NF-KB triggers early induction of LPS-responsive genes. C/EBP $\delta$ further enhances the gene transcription and acts together with NF-KB to obtain maximal transcription of those genes, thereby contributing to the amplification and persistence of inflammation. Meanwhile, NF-KB induces transcription of ATF-3. ATF-3 subsequently suppresses C/EBP $\delta$ transcription, by which it suppresses the inflammatory response. ${ }^{11,12}$

Although transcriptional regulation of inflammatory gene expression has been extensively studied, post-transcriptional regulation remains largely unknown. MCPIP1, also known as regnase- 1 and $Z$ c3h12a, was initially identified as the most highly induced protein by monocyte chemotactic protein 1 (MCP1). ${ }^{13}$ MCPIP1 is an endonuclease that selectively promotes destabilization of mRNAs that encode certain inflammatory cytokines, signal transducers and transcription factors. ${ }^{14-18}$ Through this central mechanism, MCPIP1 serves as an essential regulator of inflammatory cell activation and immune homeostasis. ${ }^{19-21}$

The biological significance of MCPIP1 has been demonstrated in MCPIP1 global knockout mice. These mice develop abnormal responses in both innate and adaptive immune cells, as manifested by splenomegaly, lymphadenopathy, heightened cytokine production and multi-organ inflammation, particularly in the lungs. ${ }^{22-24}$ The specific roles of myeloid MCPIP1 in the pathogenesis of inflammatory diseases, however, remain unknown. The goal of the current study was to determine the specific role of myeloid MCPIP1 in LPS-induced inflammation, with an emphasis on the pathological consequences in the lungs.

\footnotetext{
${ }^{1}$ Department of Biomedical Science and Shock/Trauma Research Center, School of Medicine, University of Missouri-Kansas City, Kansas City, Missouri, MO, USA; ${ }^{2}$ Institute of Translational Medicine, Nanchang University, Nanchang, Jiangxi, P. R. China; ${ }^{3}$ Department of Cell Biology and Anatomy, University of South Carolina School of Medicine, Columbia, SC, USA; ${ }^{4}$ Division of Molecular Biology and Biochemistry, School of Biological Sciences, University of Missouri-Kansas City, Kansas City, Missouri, MO, USA; ${ }^{5}$ Division of

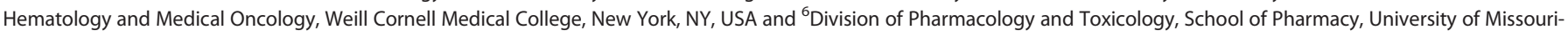
Kansas City, Kansas City, Missouri, MO, USA.

Correspondence: M Fu (fum@umkc.edu)

${ }^{7}$ These authors contributed equally to this work.

Received 26 May 2017; revised 21 September 2017; accepted 29 October 2017
} 
To accomplish this, we generated myeloid-specific MCPIP1 knockout mice (M-Mcpip $1^{-1-}$ ) by crossing a floxed mouse line with mice expressing the Cre recombinase transgene under the control of the Lysozyme M promoter. We also characterized the therapeutic potential of enhancing the MCPIP1 protein levels in protecting against LPS-induced lung injury.

\section{METHODS}

Generation of mice with a Floxed Mcpip1 allele and cell-specific knockouts

Two C57BL/6 mouse embryonic stem cell clones (HEPD0517-2-B05 and HEPD0517-2-G04) containing MCPIP1 conditional gene knock-out mutations were purchased from the European Conditional Mouse Mutagenesis Program (EUCOMM) and confirmed by Southern blot. These clones were sent to the University of Missouri Transgenic Animal Core, which produced heterozygous mice with the targeted allele. Then, we crossed this mouse line with a Pgk-Flp transgenic mouse line to remove the lacZ-neo cassette from the mouse genome and obtained a Mcpip $1^{\text {flox/+ }}$ mouse line, with two loxp sites flanking the two sides of exon 3 of the Mcpip1 gene (Figure 1a). This mouse line was further interbred to produce Mcpip $1^{\text {fl/fl }}$ mice. To produce myeloid-specific MCPIP1 knockout mice, MCPIP1 ${ }^{\text {fl/fl }}$ mice were crossed with myeloid-specific Cre-expressing transgenic mice (LysM-Cre, Stock\#: 004781, Jackson Laboratory). The resultant mice were designated as $\mathrm{M}-\mathrm{Mcpip} \mathrm{1}^{-1}$. Genotyping for loxP insertion was performed by PCR using the following primers: GCCTTCCTGATCCTATTGGAG (wild-type), GAGATGGCGCAGCGCAATTAAT (knock-out) and GCCTCTTGTCACTC CCTCCTCC (common). Genotyping for LysMCre included the following primers: TTACAGTCGGCCAGGCTGAC (wild-type), CCCAGAAATGCCAGAT TACG (mutant) and CTTGGGCTGCCAGAATTTCTC (common). The mice were housed in a pathogen-free animal facility at $25^{\circ} \mathrm{C}$ and were illuminated by 12:12-h light-dark cycles. The mice were provided with standard rodent chow and water ad libitum. All of the animal breeding and other procedures were approved by the Institutional Animal Care and Use Committee of University of Missouri Kansas City and followed the Institutional and US National Institutes of Health guidelines.

\section{LPS challenge in mice}

Mcpip $1^{\mathrm{f} / \mathrm{fl}}$ and M-Mcpip $1^{-/-}$mice at 2-months of age were used. Mice were challenged by i.p. injection of LPS at a dose of $25 \mathrm{mg} / \mathrm{kg}$ (O127:B8; Sigma-Aldrich) in $200 \mu \mathrm{l}$ sterile saline. After injection, the mice were closely monitored for general condition and survival. At $8 \mathrm{~h}$ after LPS challenge, the mice were euthanized, and serum and organs were collected for ELISA analyses and histological examinations. For the study of the effects of MI-2 on mice survival, C57BL/6 mice from the Jackson Laboratory were divided into two groups: one group was only injected with a lethal dose of LPS $(40 \mathrm{mg} / \mathrm{kg}$ body weight, i.p.); the other group was pre-treated with MI-2 ( $25 \mathrm{mg} / \mathrm{Kg}$ body weight, i.p.) at $2 \mathrm{~h}$ before LPS injection and another dose at $2 \mathrm{~h}$ post-LPS injection. All mice were closely monitored, and a 'moribund status' was equated with death to minimize the discomfort of the mice. The survival rate was recorded. For the study of $\mathrm{Ml}-2$ on LPS-induced inflammation and lung injury, adult C57BL/6 mice were divided into four groups. The first group of mice were treated with Ml-2 ( $25 \mathrm{mg} /$ body weight, i.p.) for $2 \mathrm{~h}$, then the mice were treated with LPS ( $25 \mathrm{mg} / \mathrm{kg}$ body weight, i.p.); the second group of mice were treated with PBS for $2 \mathrm{~h}$, then the mice were treated with LPS; the third group of mice was injected with LPS for $2 \mathrm{~h}$ and then treated with MI-2; the fourth group of mice were treated with PBS only. All mice were sacrificed after $8 \mathrm{~h}$ of LPS injection, and the sera and lungs were collected for ELISA, immunoblot and GPCR analysis. All experiments were approved by the Institutional Animal Care and Use Committee of University of Missouri Kansas City.

\section{Cells}

The mouse macrophage RAW264.7 cell line and the human THP1 monocyte cell line were obtained from the American Type Culture Collection and maintained in RPMI 1640 medium supplemented with $2 \mathrm{mM}$ Glutamine, $100 \mathrm{U} / \mathrm{ml}$ penicillin and streptomycin, and $10 \% \mathrm{FBS}$ (endotoxin $<1 \mathrm{ng} / \mathrm{ml}$; Sigma-Aldrich). Mouse BMDMs were generated from BM stem cells that were obtained from femurs of male Mcpip $1^{\mathrm{f} / \mathrm{fl}}$ and $\mathrm{M}-\mathrm{Mcpip} 1^{-1-}$ mice, as described previously. ${ }^{23}$ Briefly, mice were euthanized by $\mathrm{CO}_{2}$ inhalation, and bone marrow cells were isolated from femurs.
After overnight culture, nonadherent bone marrow cells were collected and cultured in RPMI 1640 medium supplemented with $10 \%$ heatinactivated FBS, $25 \mathrm{mM}$ HEPES, $2 \mathrm{mM}$ Glutamine, $100 \mathrm{U} / \mathrm{ml}$ penicillin, $100 \mu \mathrm{g} / \mathrm{ml}$ streptomycin, plus 30\% (v/v) L929 cell-conditioned medium. Adherent macrophage monolayers were obtained and their purity were determined by flow cytometric analysis. Differentiated BMDMs were then harvested by gently scraping the cells from the dishes using a rubber spatula and seeded onto $100-\mathrm{mm}$ petri dishes for experiments. Cells were subjected to serum starvation for $16 \mathrm{~h}$ in macrophage serum-free medium and then treated with $1 \mu \mathrm{g} / \mathrm{ml}$ LPS for different time points. Human primary monocytes were purchased from Lonza and cultured with the specific medium provided by Lonza. The primary peritoneal macrophages were isolated by flushing the peritoneal cavity with PBS.

\section{Reagents}

pCMV-luc-C/EBPS3'UTR were purchased from GeneCopoeia. A plasmid containing human C/EBPS CDNA and full-length $3^{\prime} U T R$ was kindly provided by Dr Esta Sterneck (NCI/NIH). Using this plasmid as a template, PCR was performed to amplify the fragments of the human C/EBPS $3^{\prime} U T R$, and these were inserted into pCMV-luc-control vector by EcoR I/Xho I. MCPIP1 rabbit polyclonal antibody was from GeneTex (GTX110807). C/ EBP $\beta, C / E B P \delta, C / E B P a, M A L T 1, B C L 10, A 20, C Y L D$, RelB and $\beta$-actin antibodies were purchased from Cell Signaling Technology. LPS (L3129, 0127:B8) was purchased from Sigma. SiRNAs targeting MCPIP1 and MALT1 were from Santa Cruz Biotechnology. qPCR primers were ordered from IDT. $\mathrm{Ml}-2$, anti-F4/80 and anti-Gr1 antibodies were purchased from R\&D Systems.

\section{Histological and immunohistochemical analysis}

Tissues were fixed in $4 \%$ phosphate-buffered paraformaldehyde and processed using standard procedures. 5 - $\mu \mathrm{m}$ paraffin tissue sections were collected and stained with $\mathrm{H} \& \mathrm{E}$. For immunostaining, sections were incubated in $3 \% \mathrm{H}_{2} \mathrm{O}_{2}$ to inactivate endogenous peroxidases, followed by Ag retrieval with heat and pressure in citrate buffer. Endogenous biotin was blocked with blocking reagents. Sections were then incubated with anti-F4/80 and anti-Gr1 Abs for $60 \mathrm{~min}$ at a 1:250 dilution, followed by HRPconjugated secondary antibodies for $30 \mathrm{~min}$. Immunolabeled $\mathrm{Ag}-\mathrm{Ab}$ complexes were visualized using SignalStain DAB substrate kit (Cell Signaling Tech.). The sections were lightly counterstained with hematoxylin before analysis.

\section{Transient transfection and luciferase assay}

Transfection and luciferase assay were performed as described previously. ${ }^{13}$ All transfections were performed in triplicate and repeated at least two times.

\section{Protein isolation and immunoblotting}

Protein isolation and immunoblotting were essentially performed as described previously. ${ }^{13}$ Tissue extracts and whole-cell lysates were prepared in RIPA buffer (Sigma) containing protease inhibitors (Complete Mini; Roche, Indianapolis, IN), respectively, cleared by centrifugation, and quantified using the Bradford assay. Denatured lysates were separated on 8-12\% Tris- $\mathrm{HCl}$ gels and transferred onto nitrocellulose membranes. Blots were incubated at $4{ }^{\circ} \mathrm{C}$ overnight with antibodies as indicated, followed by incubation with HRP-conjugated goat anti-rabbit IgG. Immune complexes were detected using $\mathrm{ECL}$ chemiluminescent substrate.

\section{Measurement of cytokine levels in sera}

Mouse serum levels of cytokines/chemokines were measured using a BioPlex Pro ${ }^{\text {TM }}$ Mouse Cytokine 23-plex Assay Kit (Bio-Rad) on a Bio-Plex system following the manufacturer's instructions.

\section{RNA isolation and quantitative PCR (qPCR)}

Total tissue or cellular RNA was isolated using TRIzol reagent, according to the manufacturer's instructions (Invitrogen). Residual genomic DNA was removed by on-column digestion with RNase-free DNase I. To determine the decay rates of cytokine transcripts, actinomycin D $(5 \mu \mathrm{g} / \mathrm{ml}$; SigmaAldrich) was added to block transcription after BMDMs were stimulated with LPS $(1 \mu \mathrm{g} / \mathrm{ml})$ for $4 \mathrm{~h}$. Total RNA was isolated at the indicated times over a 2-h time course after the addition of actinomycin D. IL-6, C/EBP $\beta$ 
a

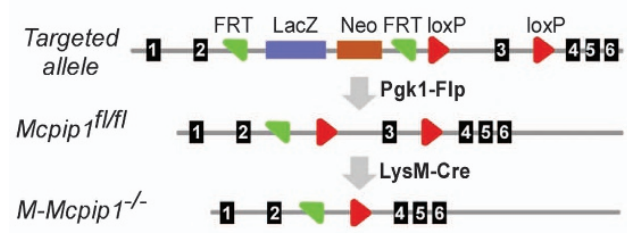

d

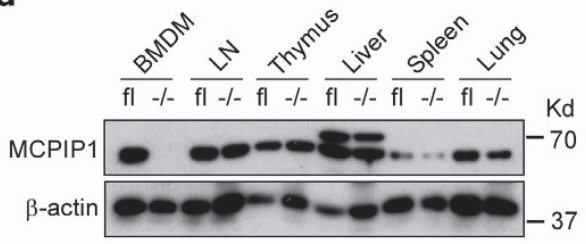

b

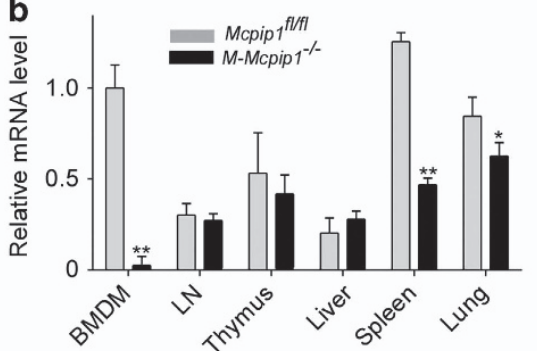

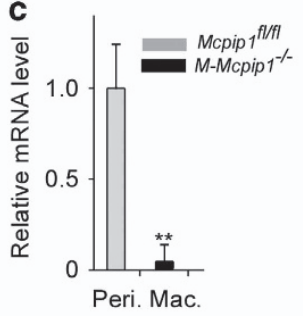

e

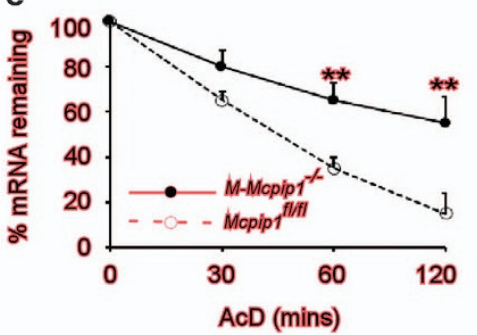

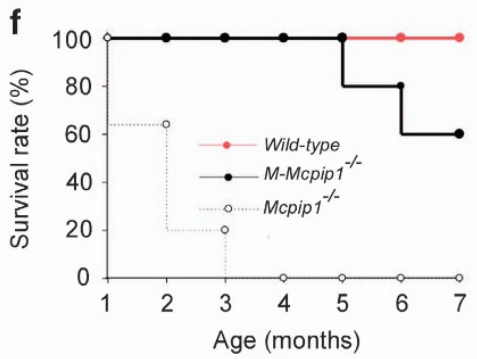

g

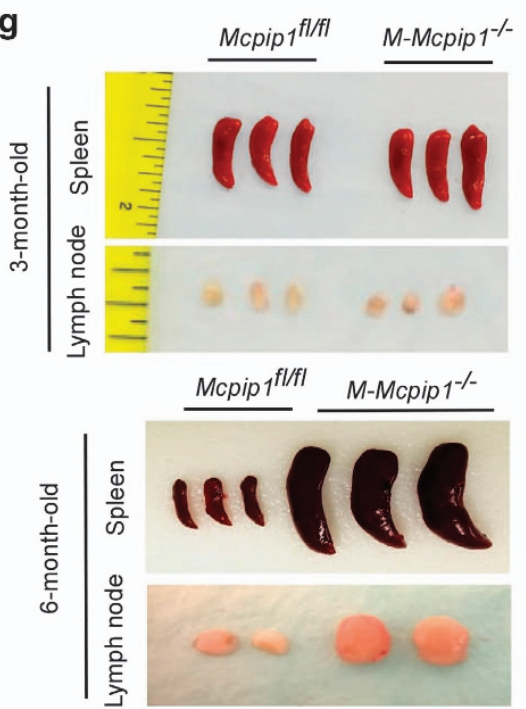

h
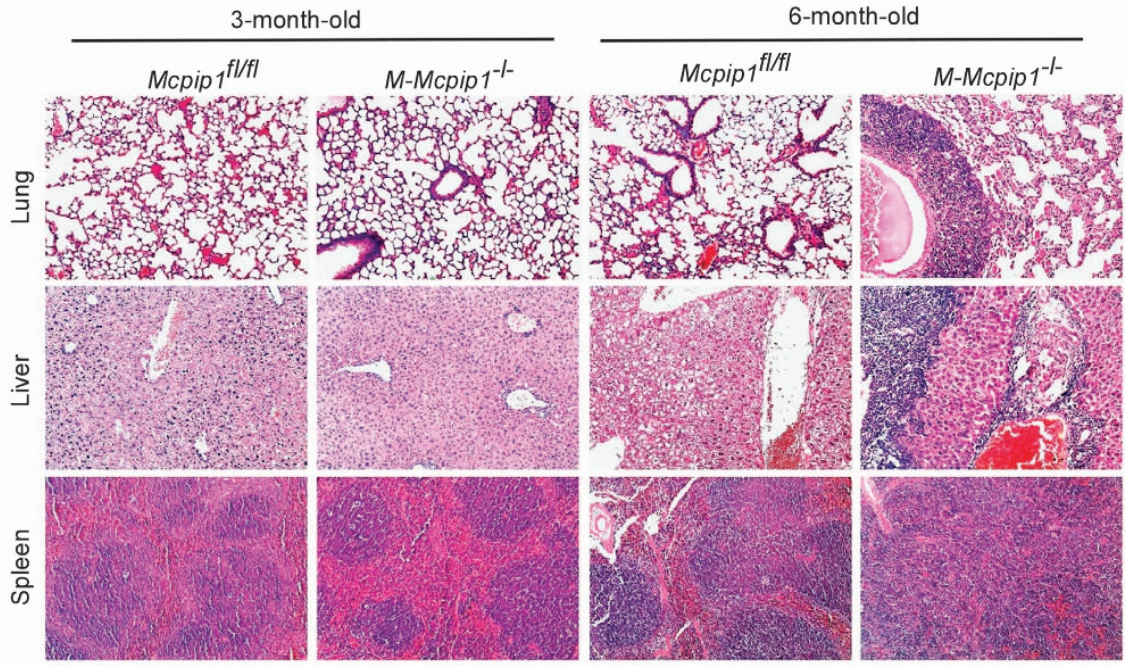

Figure 1. Generation and characterization of M-Mcpip $1^{-1-}$ mice. (a) Schematic map of the strategy used for generating the Mcpip1 conditional targeted allele, Mcpip $1^{\text {floxflox }}$, and M-Mcpip $1^{-1-}$ mice. (b) qPCR analysis of the MCPIP1 mRNA levels in BMDMs and the indicated tissues collected from Mcpip $1^{\text {ffl }}$ and M-Mcpip $1^{-1-}$ mice. Data are representative of three independent experiments with 3 mice per group. ${ }^{*} P<0.05,{ }^{* *} P<0.001$ by Student's $t$-test. (c) qPCR analysis of the MCPIP1 mRNA levels in peritoneal macrophages collected from Mcpip ${ }^{1 f f}$ and M-Mcpip $1^{-1-}$ mice. Data are representative of three independent experiments with 3 mice per group. ${ }^{* *} P<0.001$ by Student's $t$-test. (d) Immunoblot analysis of the MCPIP1 protein levels in BMDMs and indicated tissues from Mcpip $1^{\text {fff }}$ and M-Mcpip $1^{-/-}$mice. $\beta$-actin served as a loading control. Data are representative of three independent experiments. (e) BMDMs from Mcpip $1^{\text {fffl }}$ and $M-M c p i p 1^{-/-}$mice were stimulated with LPS $(1 \mu \mathrm{g} / \mathrm{ml})$ for $4 \mathrm{~h}$ and then incubated with AcD $(5 \mu \mathrm{g} / \mathrm{ml})$ for different time points as indicated. The mRNA levels of IL-6 were measured by qPCR and normalized as $100 \%$ at the 0 -hr time point. Data were presented as the means \pm s.d., $n=4$. (f) Survival rate of Mcpip1 global knockout (Mcpip1 ${ }^{-1-}$ ) mice, myeloid-specific Mcpip1 knockout (M-Mcpip1 ${ }^{-/-}$) mice and wild-type mice ( $n=10$ ). (g) Photographs of spleens and lymph nodes collected from Mcpip $1^{\text {ffl }}$ and M-Mcpip $1^{-1-}$ mice at 3 months and 6 months of age. (h) Hematoxylin-and-eosin staining of lung and liver sections from Mcpip ${ }^{\text {fff }}$ and M-Mcpip $1^{-/-}$mice at 4 months of age or 6 months of age, respectively. Original magnification is $100 \times$. Data are representative of three independent experiments.

and C/EBP $\delta$ transcript levels were determined by qPCR. First-strand CDNA was synthesized using oligo(dT) $12-18$ primers and SuperScript III Reverse Transcriptase. Real-time PCR was performed using SYBR Green and the ABI Step-One Plus Detection System (Applied Biosystems). Primers were designed and compared with the current mouse genome reference sequence using BLAST to ensure that no cross-reactivity with other genes would occur. The results were normalized against the $\beta$-actin transcript as an internal control and were then used to calculate expression levels according to the $\Delta \Delta$ cycle threshold method. All data were expressed in terms of fold-change relative to the unstimulated sample, which was set as 1 , unless otherwise specified. The primers were validated for their amplification efficiency and specificity prior to being used in the study. The primer sequences are presented in Supplementary Table 1.

\section{Statistics}

Data were expressed as the means \pm s.d. For comparison between two groups, the unpaired Student's $t$ test was used. For multiple comparisons, analysis of variance followed by unpaired Student's $t$ test was used. For mouse survival rates, the log-rank Mantel-Cox test was used. A value of $P<0.05$ was considered statistically significant. 
a
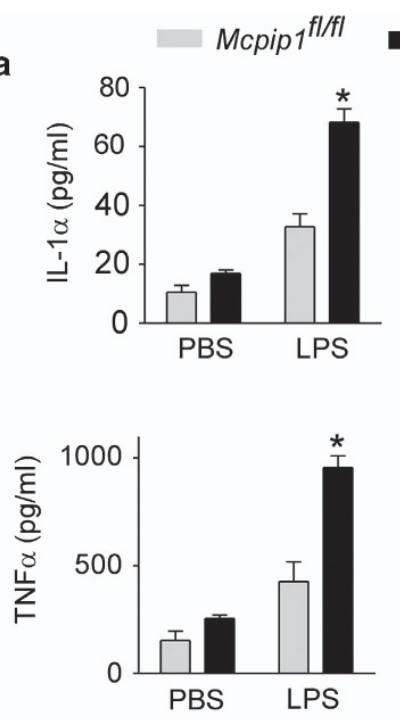
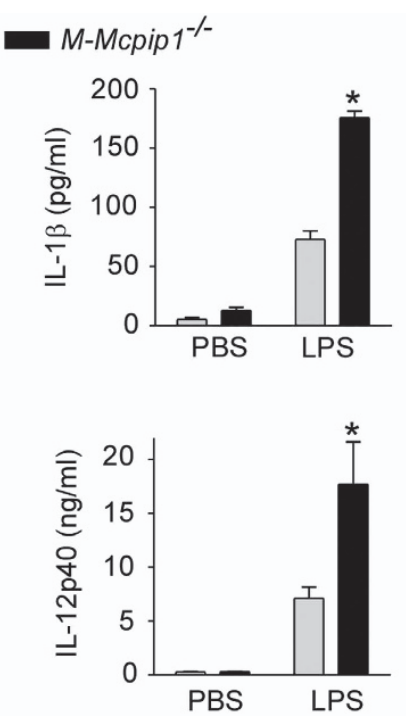
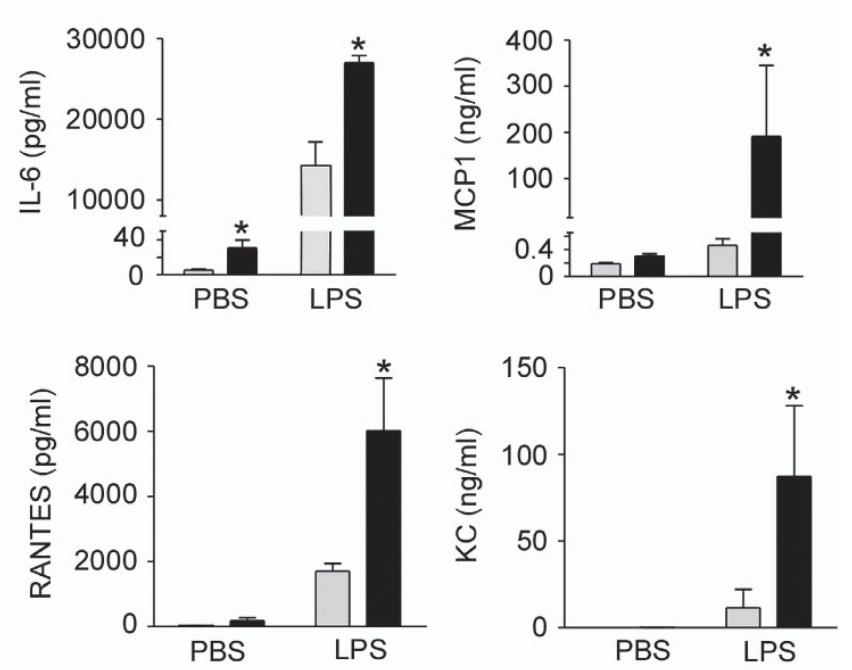

b

PBS
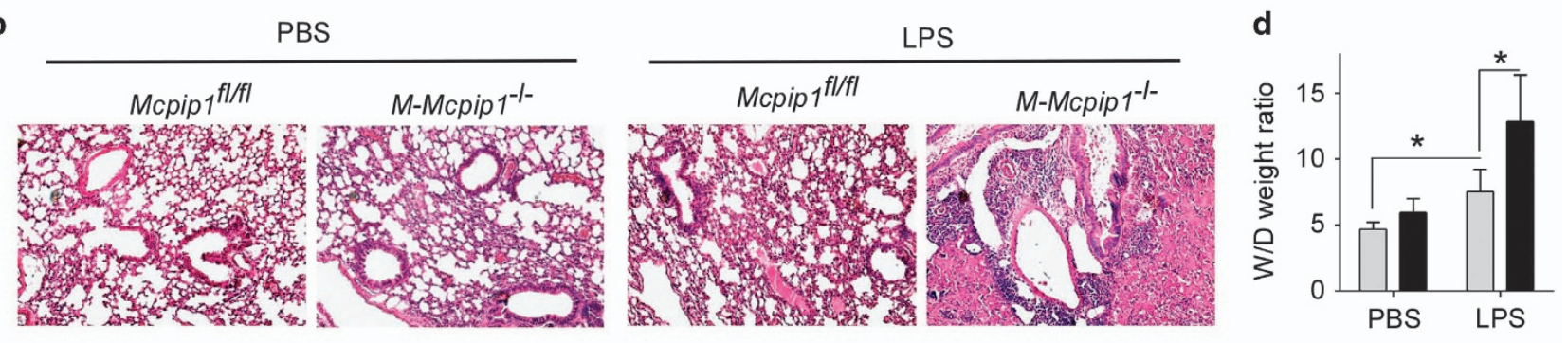

C

PBS

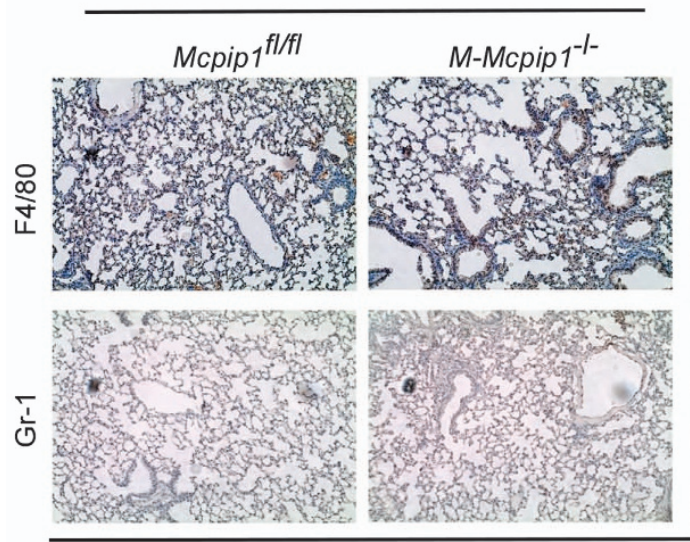

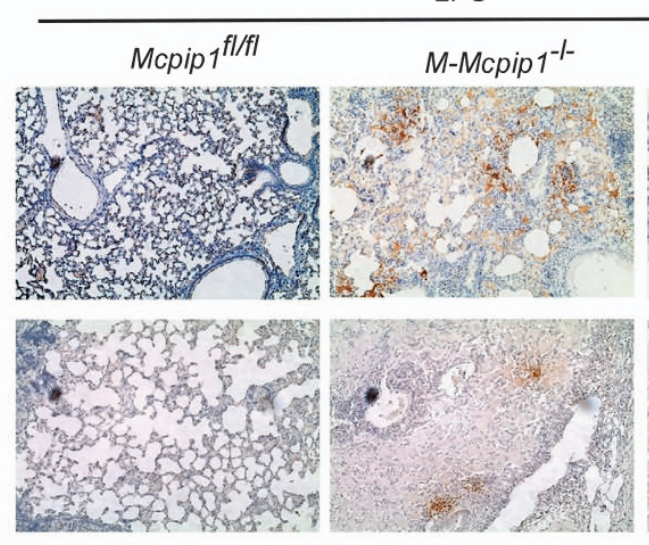

100X
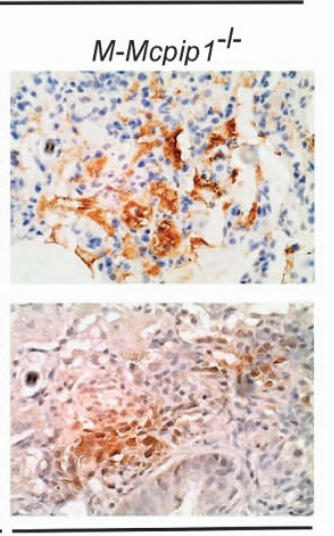

$400 \mathrm{X}$

Figure 2. Mice with myeloid-specific knockout of MCPIP1 are susceptible to LPS-induced inflammation and lung injury. (a) Serum levels of proinflammatory cytokines and chemokines in Mcpip $1^{\text {fff }}$ and M-Mcpip $1^{-/-}$mic, treated intraperitoneally with PBS or LPS for 8 h. Data are presented as the means \pm s.d. $(n=5)$. ${ }^{*} P<0.05$, versus Mcpip $1^{\text {fff }}$ group. (b) H\&E staining of lung sections from Mcpip $1^{\text {fff }}$ and M-Mcpip $1^{-1-}$ mice at 2 months of age treated intraperitoneally with PBS or LPS for $8 \mathrm{~h}$. Original magnification is $100 \times$. Data are representative of three independent experiments. (c) Immunohistological staining of lung sections from Mcpip $1^{\text {ffl }}$ and M-Mcpip $1^{-1-}$ mice at 2 months of age treated intraperitoneally with PBS or LPS for $8 \mathrm{~h}$, with anti-F4/80 or Gr-1 antibodies. Original magnification is $100 \times$ or $400 \times$, as indicated. Data are representative of three independent experiments. (d) Changes of lung wet-to-dry ratios in Mcpip ${ }^{\text {ffl }}$ and M-Mcpip1 ${ }^{-1-}$ mice treated intraperitoneally with PBS or LPS for $8 \mathrm{~h}$. Data are presented as the means \pm s.d., ${ }^{*} P<0.05$ by Student's $t$-test.

\section{RESULTS}

Myeloid-specific MCPIP1 knockout mice develop late-onset inflammatory syndrome

To study cell-specific functions of MCPIP1 in vivo, we generated a Mcpip1-floxed mouse line in a C57BL/6 background. As shown in Figure $1 \mathrm{a}$, the targeted allele contains two loxp sites flanking the two sides of exon 3 of the Mcpip1 gene. After crossing with a Pgk-
Flp transgenic mouse line to remove the lacZ-neo cassette, we obtained a Mcpip $1^{\mathrm{fl} /+}$ mouse line. This mouse line was further interbred to produce Mcpip $1^{\mathrm{f} / \mathrm{fl}}$ mice. By crossing Mcpip $1^{\mathrm{fl} / \mathrm{fl}}$ mice with myeloid-specific transgenic mice of Cre (LysM-Cre, Stock\#: 004781, Jackson Labs), ${ }^{25}$ we generated myeloid-specific MCPIP1 knockout (M-Mcpip $1^{-1-}$ ) mice. To verify that the Mcpip1 gene was successfully and specifically deleted in myeloid cells, such as 
macrophages, we isolated bone-marrow derived macrophages (BMDMs) and other tissues from both Mcpip $1^{\text {fl/fl }}$ and M-Mcpip $1^{-/-}$ mice. Real-time quantitative PCR (qPCR) analysis showed specific deletion of MCPIP1 mRNA in BMDMs, but not in thymus and lymph node tissues, which predominantly contain lymphocytes (Figure 1b). Deletion of MCPIP1 mRNA was further confirmed in primary peritoneal macrophages by qPCR (Figure 1c). Immunoblot analysis further showed that the MCPIP1 protein was specifically deleted in BMDMs, but not in liver, thymus and lymph node tissues (Figure 1d). Both the MCPIP1 mRNA and protein levels were also decreased to an extent in the spleen and lungs, likely attributable to the high numbers of macrophages present in these tissues (Figures $1 \mathrm{~b}$ and d). IL-6 mRNA is a known target of MCPIP1 RNase. $^{22}$ As shown in Figure 1e, the decay of IL-6 mRNA was significantly delayed in M-Mcpip 1 $1^{-/-}$BMDMs, suggesting that the MCPIP1 is functionally lost in knockout macrophages. These results confirmed that the Mcpip1 gene was specifically deleted in macrophages from M-Mcpip $1^{-1-}$ mice.

M-Mcpip $1^{-/-}$mice were born at the expected Mendelian ratio and had no gross abnormalities up to 5 months of age. However, after 5 months of age, mice failed to thrive and developed cachexia (decreased body weight), splenomegaly, lymphadenopathy, multi-organ inflammation and premature death, comparable to that observed in MCPIP1 global knockout mice, but at a much older age. As shown in Figure 1f, global MCPIP1 knockout mice all died within 4 months, whereas myeloid-specific MCPIP1 knockout mice began to die after 5 months, and $60 \%$ of these mice were alive at 7 months of age. At the same time, all wild-type mice survived. The sizes of the spleens and lymph nodes of 3month-old M-Mcpip $1^{-/-}$mice appeared normal, but M-Mcpip $1^{-1-}$ mice developed spontaneous splenomegaly and lymphadenopathy at 6 months of age (Figure 1g). As shown in Figure 1h, minimal inflammation was observed in the lungs and liver of M-Mcpip $1^{-/-}$mice at 3 months of age, whereas inflammatory cell infiltration was marked in the lungs and liver from M-Mcpip $1^{-/-}$ mice at 6 months of age. Similarly, minimal architectural changes in the spleens of M-Mcpip $1^{-1-}$ mice were observed at 3 months of age, whereas the architecture of the spleen of $\mathrm{M}-\mathrm{Mcpip} 1^{-/-}$mice at 6 months of age was disorganized due to marked expansion of the white pulp. A more detailed phenotypic characterization of M-Mcpip $1^{-/-}$mice is being performed and will be reported elsewhere.

Myeloid MCPIP1 suppresses LPS-induced inflammation and lung injury

To determine whether expression of MCPIP1 in myeloid cells is critical for protecting against LPS-induced inflammation and lung injury, 2-month-old Mcpip $1^{\mathrm{f} / \mathrm{fl}}$ and M-Mcpip $1^{-1-}$ mice were injected with LPS ( $25 \mathrm{mg} / \mathrm{kg}$ body weight, i.p.). After $8 \mathrm{~h}$, mice were euthanized, serum was collected to measure cytokines, and the lungs were fixed and analyzed by H\&E staining. As shown in Figure 2a, LPS inoculation induced higher serum concentrations of proinflammatory cytokines and chemokines, including IL-1a, IL-1 $\beta$, IL-6, IL-12p40, TNFa, MCP1, RANTES and KC, in M-Mcpip $1^{-1-}$ mice compared to Mcpip $1^{\text {fl/fl }}$ controls. Additionally, the levels of MIP-1a, MIP-1 $\beta$, GM-CSF, G-CSF, IL-3, IL-5, IL-12p70 and IL-13 were also significantly greater in M-Mcpip $1^{-1-}$ mice than in Mcpip $1^{\mathrm{fl} / \mathrm{fl}}$ controls inoculated with LPS (Supplementary Figure S1). Moreover, without LPS challenge, there was essentially no inflammation in the lungs of 2 -month-old Mcpip $1^{\mathrm{f} / \mathrm{fl}}$ mice, and relatively minor inflammation was observed in the lungs of $\mathrm{M}$-Mcpip $1^{-/}$mice. With LPS challenge, pulmonary inflammation in both mouse strains was enhanced, but was much more severe in M-Mcpip $1^{-/-}$ mice compared to Mcpip $1^{\mathrm{f} / \mathrm{fl}}$ mice (Figure $2 \mathrm{~b}$ ). Inflammatory cells observed in the lungs of $\mathrm{M}-\mathrm{Mcpip} 1^{-/-}$mice were primarily macrophages and neutrophils, as shown by staining with antiF4/80 and anti-Gr-1 antibodies (Figure 2c). Activated macrophages are known to secrete inflammatory cytokines, reactive oxygen species and enzymes, which can have damaging effects on epithelial-endothelial barriers in the lungs, leading to pulmonary edema, an important component of the severe form of acute lung injury, acute respiratory distress syndrome. ${ }^{26}$ Pulmonary edema, measured as a significant increase in the wet-to-dry lung weight ratio, was observed in both strains with LPS challenge, but was much more severe in $M-M c p i p 1^{-/-}$mice than in Mcpip $1^{\mathrm{fl} / \mathrm{fl}}$ controls (Figure $2 \mathrm{~d}$ ). Furthermore, we measured the mRNA levels of inflammatory markers for macrophage activation in the lungs of both strains. As shown in Supplementary Figure S2, without LPS challenge, the mRNA levels of CXCL1, CXCL2, CCL4, IL-6, MCP1, $\mathrm{IL}-1 \beta$, and $\mathrm{CXCL} 13$ were higher in the lungs of $\mathrm{M}-\mathrm{Mcp}$ cpip $1^{-/-}$mice than in Mcpip $1^{\mathrm{f} / \mathrm{fl}}$ controls. After LPS challenge, the mRNA levels for these markers increased to a much greater extent in the lungs of $\mathrm{M}-\mathrm{Mcpip} 1^{-/-}$mice compared to Mcpip $1^{\mathrm{f} / \mathrm{fl}}$ controls. By contrast, the anti-inflammatory cytokine IL-10 was decreased in LPS-challenged M-Mcpip $1^{-/-}$mice. The survival rate within the time window was closely observed, and all mice from both genotypes survived under this condition. Thus, deletion of MCPIP1 in myeloid cells rendered mice highly susceptible to LPS-induced inflammation and lung injury.

Identification of C/EBP $\beta$ and C/EBP $\delta$ mRNAs as targets of MCPIP1 RNase in BMDMs

To explore the mechanisms by which a deficiency of MCPIP1 in macrophages bolsters the response to LPS, the mRNA levels of several inflammatory markers were measured in BMDMs stimulated with LPS $(1 \mu \mathrm{g} / \mathrm{ml})$ for 0 to $8 \mathrm{~h}$ (Figure 3a). First, we confirmed that the MCPIP1 mRNA levels were extremely low to nondetectable in LPS-stimulated BMDMs from M-MCPIP1 ${ }^{-/-}$mice. IL-6 and IL-1 $\beta$ mRNAs, two known targets of MCPIP1 RNase, ${ }^{21,22}$ were significantly increased in LPS-stimulated BMDMs from M-Mcpip $1^{-1-}$ versus control mice. The TNFa mRNA levels were not significantly different in LPS-stimulated BMDMs from M-Mcpip $1^{-1-}$ compared to controls, and it is known that TNFa mRNA is not a direct target of MCPIP1 RNase. ${ }^{22}$ Interestingly, mRNAs for both C/EBP $\beta$ and C/EBPS were also significantly increased in LPS-stimulated BMDMs from M-Mcpip $1^{-/-}$mice compared to controls (Figure 3a). Immunoblot analysis further confirmed that the protein levels of C/EBP $\beta$ and C/EBP $\delta$ were higher in LPS-stimulated lungs from M-Mcpip $1^{-/-}$mice than Mcpip ${ }^{f / f l}$ controls (Figures $3 b$ and $c$ ). These intriguing results suggest that C/EBP $\beta$ and C/EBP $\delta$ mRNAs may be direct targets of MCPIP1. To further examine whether the MCPIP1 deficiency affects mRNA degradation of C/EBP $\beta$ and C/EBPS, BMDMs were first treated with LPS for $4 \mathrm{~h}$ and then incubated with actinomycin $\mathrm{D}$ $(A c D, 5 \mu \mathrm{g} / \mathrm{ml})$ for different times, as indicated in Figure $3 \mathrm{~d}$. $\mathrm{qPCR}$ analysis showed that the mRNA levels of C/EBP $\beta$ and C/EBP $\delta$ were more stabilized in the cells from M-Mcpip $1^{-1-}$ mice than from Mcpip ${ }^{f / f l}$ mice (Figure $3 d$ ). As a negative control, the decay of TNF mRNA was not altered in cells. It was recently reported that C/ EBP $\beta$ mRNA is a direct target of MCPIP1 RNase. ${ }^{27}$ Our results further confirm that $C / E B P \beta$ is also regulated in macrophages. It has previously been reported that MCPIP1 RNase targets the $3^{\prime}$ UTR of its mRNA substrates, thereby promoting degradation. ${ }^{22} \mathrm{We}$ therefore focused on studying the C/EBP $\delta 3^{\prime} U T R$. To examine whether MCPIP1 promotes degradation of C/EBP $\delta$ mRNA by targeting its $3^{\prime} \mathrm{UTR}$, luciferase reporters containing the mouse $\mathrm{C} /$ EBPS 3'UTR (1-241) (GeneCopoeia) and human C/EBPS 3'UTR (1$397)$, as well as control reporters, were co-transfected with an empty vector or Flag-MCPIP1 in Raw264.7 cells by electroporation (Amaxa). As shown in Figure $3 e$, both reporters containing the $\mathrm{C} /$ EBPS 3'UTR were significantly suppressed by overexpression of MCPIP1. As previously reported, MCPIP1 preferentially binds to stem-loop-like structures. ${ }^{14}$ We identified three stem-loops on human C/EBPS 3'UTR by mfold (Figure 3f). Through serial deletion, 
we further defined the second stem-loop (180-192) as the putative binding site of MCPIP1 (Figure $3 \mathrm{~g}$ ). As both C/EBP $\beta$ and C/EBP $\delta$ are critical regulators of proinflammatory cytokines and chemokines, ${ }^{28,29}$ it appears that one mechanism by which myeloid MCPIP1 suppresses LPS-induced inflammation and lung injury is to promote $\mathrm{C} / \mathrm{EBP} \beta$ and $\mathrm{C} / \mathrm{EBP} \delta$ mRNA degradation.
Pharmacological inhibition of MALT1 protease activity selectively increased the MCPIP1 protein levels in macrophages and inhibited macrophage activation

It has previously been reported that MALT1 protease cleaves MCPIP1 in T cells. ${ }^{30}$ However, it is currently unknown whether MALT1 protease also cleaves MCPIP1 in macrophages. MI-2 is a
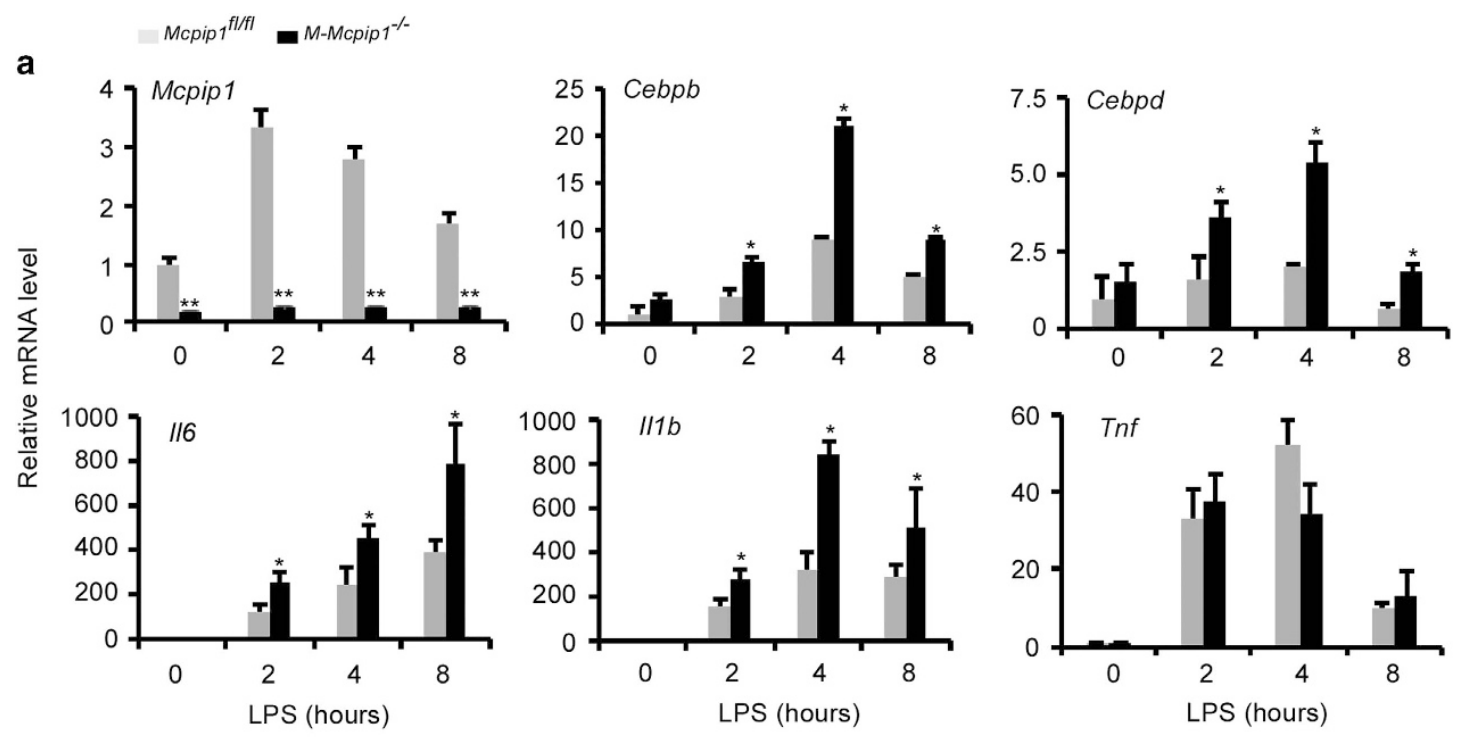

b
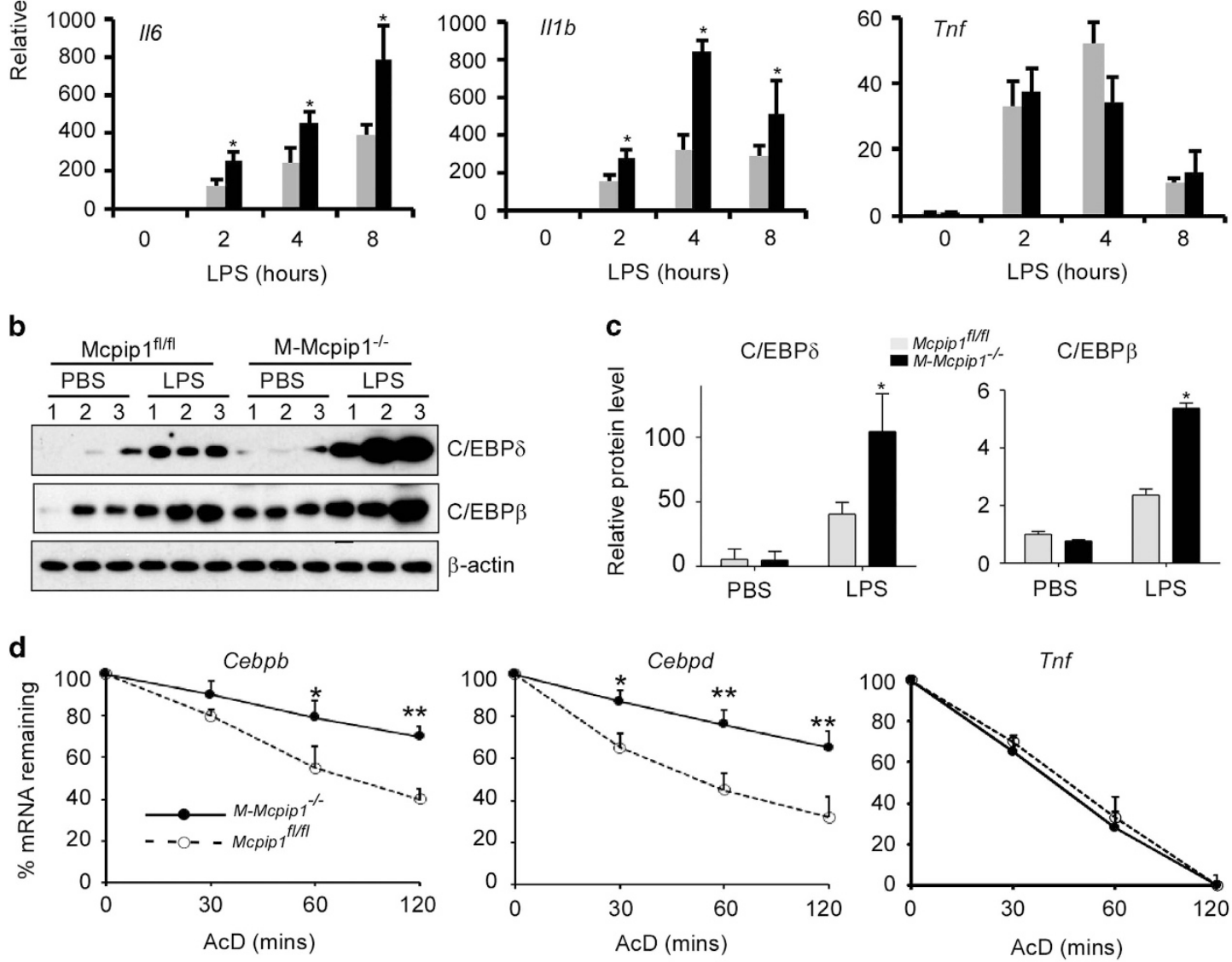

e

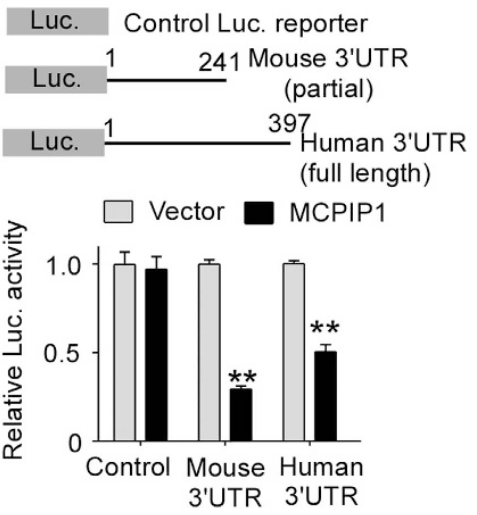

f C/EBP SL1 (147-158)

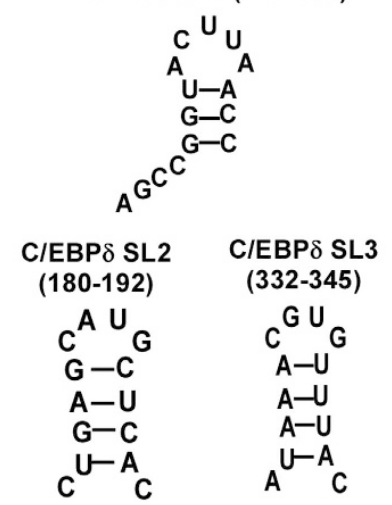

g
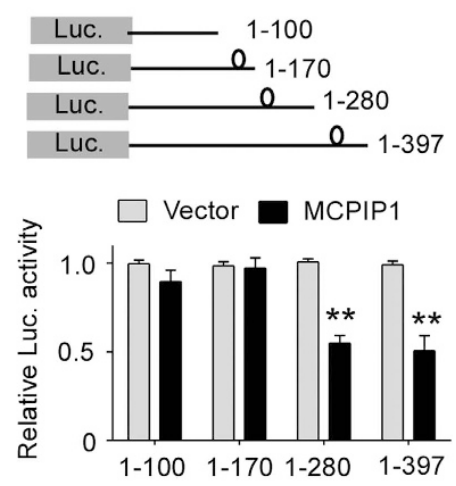
specific inhibitor of MALT1 protease activity. ${ }^{31}$ To examine whether pharmacological inhibition of MALT1 protease activity by MI-2 enhanced the MCPIP1 protein levels in macrophages, Raw264.7 cells, a murine macrophage cell line, were treated with different doses of $\mathrm{Ml}-2$ for $8 \mathrm{~h}$ or with $1 \mu \mathrm{M} \mathrm{Ml}-2$ for different lengths of time. As shown in Figures $4 \mathrm{a}$ and $\mathrm{b}, \mathrm{Ml}-2$ significantly increased the MCPIP1 protein levels in macrophages in time- and dose-dependent manners. As previously reported, MALT1 protease targets several signal regulators, such as A20, CYLD, BCL10 and RelB. ${ }^{32-35}$ To examine whether Ml-2 also enhanced these protein levels, we incubated macrophages with or without $1 \mu \mathrm{M}$ Ml-2 for $1 \mathrm{~h}$ and then stimulated the cells with $1 \mu \mathrm{g} / \mathrm{ml}$ LPS for $4 \mathrm{~h}$. The cell lysates were analyzed by immunoblot with different antibodies, as indicated in Figure 4c. As shown in Figure 4c, MALT1 is constitutively expressed in macrophages, and its expression was not affected by treatment with MI-2 and/or LPS. Increased expression of A20, BCL10, and RelB was induced by LPS, but not affected by MI-2 treatment. CYLD expression was not affected by LPS or MI-2 treatment. MCPIP1 expression was increased by Ml-2 treatment, and this effect was more dramatic in LPS-stimulated cells (Figures $4 c$ and d). By contrast, the C/EBP $\delta$ levels were decreased by $\mathrm{Ml}-2$ treatment, and this effect was particularly dramatic in LPS-stimulated cells (Figures $4 c$ and d). By contrast, the $\mathrm{C} / \mathrm{EBPa}$ and $\mathrm{C} / \mathrm{EBP} \beta$ protein levels were not significantly altered by either MI-2 or LPS treatment. These results suggest that Ml-2 selectively enhanced the MCPIP1 protein levels in LPS-stimulated macrophages by preventing MALT1-mediated degradation of MCPIP1. These results also suggest that enhanced MCPIP1 levels, due to inhibition of MALT1, result in the enhanced degradation of C/EBPS,

To examine whether MI-2 suppressed LPS-induced macrophage activation, Raw264.7 cells were pretreated with or without $1 \mu \mathrm{M}$ $\mathrm{Ml}-2$ for $1 \mathrm{~h}$ and then stimulated with $1 \mu \mathrm{g} / \mathrm{ml}$ LPS for $4 \mathrm{~h}$. The mRNA levels of macrophage activation markers were then analyzed by qPCR. As shown in Figure 4e, the mRNA levels of TNFa, IL-1 $\beta$ and IL-6 were significantly increased by LPS stimulation, as expected. Induction of IL-1 $\beta$ and IL-6, but not TNFa mRNA expression, was dramatically inhibited by $\mathrm{Ml}-2$ treatment. These observations are consistent with the conclusion that MCPIP1 degrades IL-1 $\beta$ and IL- 6 , but not TNFa mRNA, and that inhibition of MALT1 with MI-2 bolsters the MCPIP1 levels, resulting in enhanced degradation of IL-1 $\beta$ and IL- 6 mRNA.

To confirm that Ml-2-mediated inhibition of macrophage activation is dependent on MCPIP1 expression, siRNA-control and siRNA-MCPIP1 were transfected into macrophages. After $24 \mathrm{~h}$, transfected cells were treated with or without Ml-2 and then stimulated with or without LPS. As shown in Figures $4 f-h$, both the MCPIP1 protein and mRNA levels were efficiently reduced by siRNA treatment. Ml-2-mediated inhibition of C/EBP $\delta$ protein expression was severely compromised by siMCPIP1 treatment.
Furthermore, MI-2-mediated inhibition of IL-1 $\beta$ and IL-6 mRNA expression was compromised by siMCPIP1 treatment. These results collectively suggest that inhibition of MALT1 activity with $\mathrm{MI}-2$ results in increased MCPIP1 levels in macrophages, which significantly inhibits macrophage inflammation by decreasing the expression levels of IL-1 $\beta, I L-6$, and C/EBP $\delta$. Similar results were also observed in THP1-derived macrophages, a human macrophage cell line (Supplementary Figure S3), and human primary monocytes (Supplementary Figure S4).

SiRNA-mediated knockdown of MALT1 also selectively increased the MCPIP1 protein levels in macrophages and inhibited macrophage activation

To exclude any non-specific effects of MI- 2 on the MCPIP1 protein levels in macrophages, Raw264.7 cells were transfected with siRNA targeting MALT1 or control siRNA. After $24 \mathrm{~h}$, transfected cells were treated with or without LPS for $4 \mathrm{~h}$. The cell lysates were collected for immunoblot analysis. As shown in Figures $5 \mathrm{a}$ and $\mathrm{b}$, the MALT1 protein levels were efficiently reduced by si-MALT1 by $80 \%$ compared to si-Control-treated cells. Consistently, the MCPIP1 protein levels were increased by si-MALT1 in resting macrophages and further increased in LPS-treated cells. By contrast, the C/EBP $\delta$ protein levels were significantly decreased by si-MALT1. Interestingly, previously reported targets of MALT1, including A20, BCL10, CYLD and RelB, were not affected by siMALT1 treatment in macrophages. These results suggest that MALT1 protease selectively cleaved MCPIP1 both in resting and activated macrophages, but did not cleave other targets that have been identified in lymphocytes, such as A20, BCL10, CYLD and RelB. The mechanisms underlying the discrimination between the two types of cell lineages remain to be further investigated. To examine whether siRNA-mediated knockdown of MALT1 suppresses LPS-induced macrophage activation, Raw264.7 cells were transfected with siRNA for MALT1 or control siRNA. After $24 \mathrm{~h}$, transfected cells were treated with or without LPS for $4 \mathrm{~h}$, and the mRNA levels of the macrophage activation markers were analyzed by qPCR. As shown in Figure $5 c$, the mRNA levels of IL-1 $\beta$, IL- 6 CCL4, CXCL2 and G-CSF were significantly increased by LPS stimulation, as expected, and these levels were dramatically suppressed by si-MALT1 treatment. However, the mRNA levels of TNFa and MCP1 were induced by LPS, but were not affected by siMALT1 treatment. The IL-10 mRNA levels were decreased by LPS but were not affected by siMALT1 treatment (Figure $5 \mathrm{c}$ ). These results demonstrate that reducing the MALT1 levels by siRNA consistently enhances the MCPIP1 protein levels in macrophages, significantly inhibiting macrophage inflammatory signaling by decreasing expression of IL-1 $\beta$, IL-6, and C/EBPS.

Figure 3. Identification of C/EBP $\beta$ and C/EBP $\delta$ mRNAs as the targets of MCPIP1 RNase. (a) qPCR analysis of the mRNA levels for MCPIP1, C/EBP $\beta$, C/EBPS, and other inflammatory cytokines in BMDMs from Mcpip $1^{\text {fff }}$ and M-Mcpip $1^{-1}$ mice treated with LPS for the indicated times. Data are representative of three independent experiments with 3 mice per group. ${ }^{*} P<0.05$ by Student's $t$-test. (b) Immunoblot analysis of the C/EBP $\beta$ and C/EBPS protein levels in the lungs of Mcpip $1^{\text {ffl }}$ and M-Mcpip $1^{-9-}$ mice treated with PBS or LPS for $8 \mathrm{~h}$. $\beta$-actin served as a loading control. (c) Fold-change of C/EBP $\beta$ and C/EBPS proteins in experiments presented in (b) were determined by densitometry and normalized to $\beta$-actin. ${ }^{*} P<0.01, * P<0.05$ by Student's $t$-test. Data are representative of three independent experiments. (d) BMDMs from Mcpip $1^{\text {ffl }}$ and M-Mcpip $1^{-/-}$mice were stimulated with LPS $(1 \mu \mathrm{g} / \mathrm{ml})$ for $4 \mathrm{~h}$ and then incubated with ACD $(5 \mu \mathrm{g} / \mathrm{ml})$ for different times as indicated. The mRNA levels were measured by qPCR and normalized to the actin mRNA levels. Data were presented as the means \pm s.d., $n=4$. (e) The reporter of Luc-Control or Luc.-mouse C/EBPS 3'UTR or Luc.-human C/EBPS 3'UTR was transfected with or without Flag-MCPIP1 into Raw264.7 cells. Twenty-four hours later, cells were collected for analysis of luciferase activity and normalized to control renilla activity. $N=4,{ }^{*} P<0.05$. ${ }^{*} P<0.01$ versus vector. Data are representative of three independent experiments. (f) The stem-loop structures on human C/EBPS $3^{\prime} U$ TR identified by mfold. (g) The serial deletion reporters, as indicated, were transfected with or without Flag-MCPIP1 into Raw264.7 cells. Twentyfour hours later, cells were collected for analysis of luciferase activity and normalized to control renilla activity. $N=4,{ }^{* *} P<0.01$ versus vector. Data are representative of three independent experiments. 
a

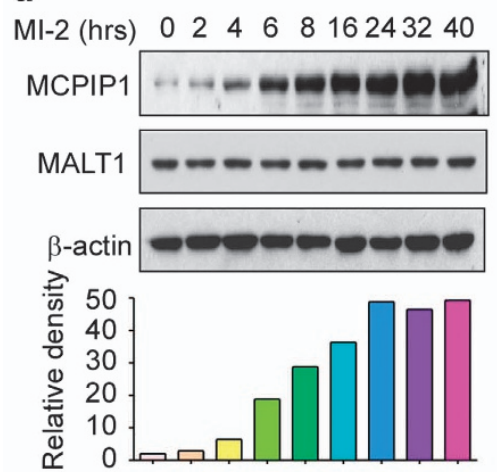

b

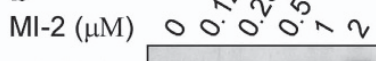
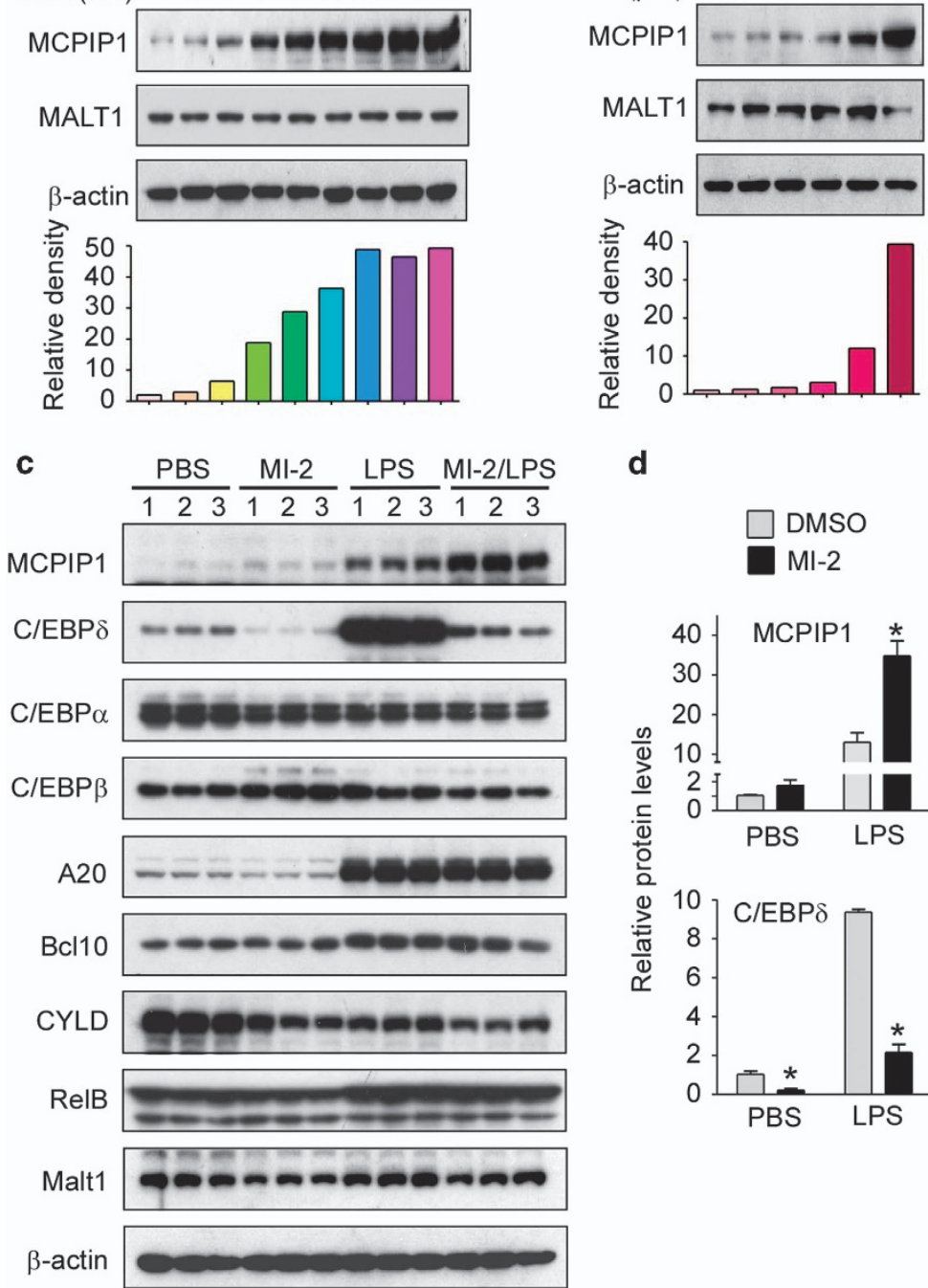

d

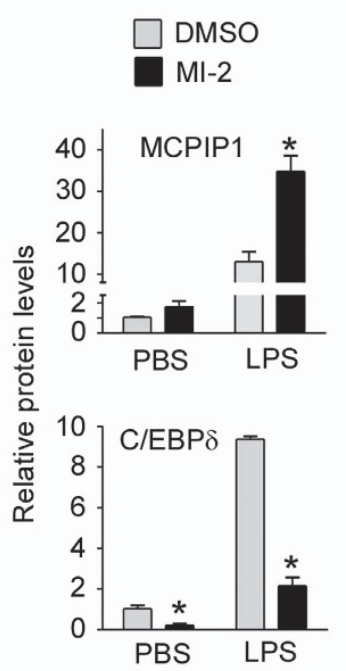

e

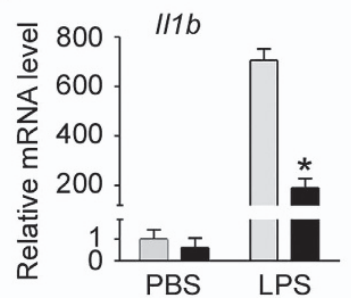

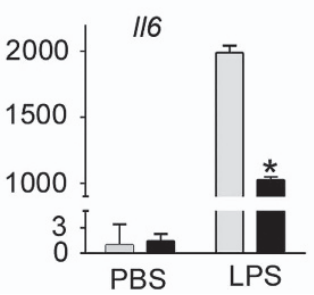

$\square$ DMSO $\square \mathrm{Ml}-2$

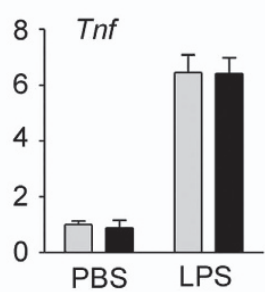

f

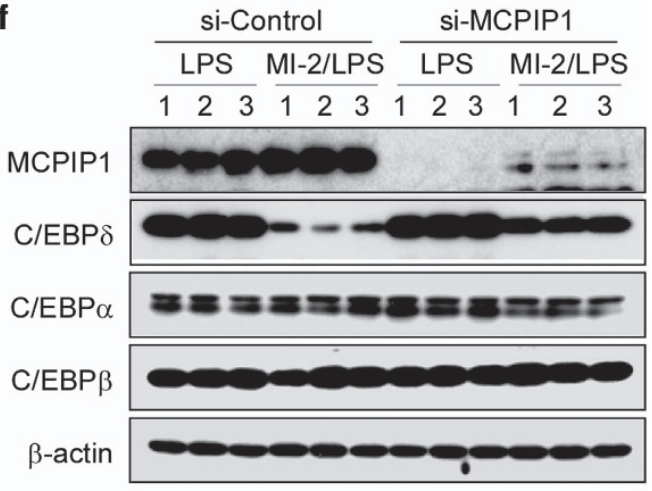

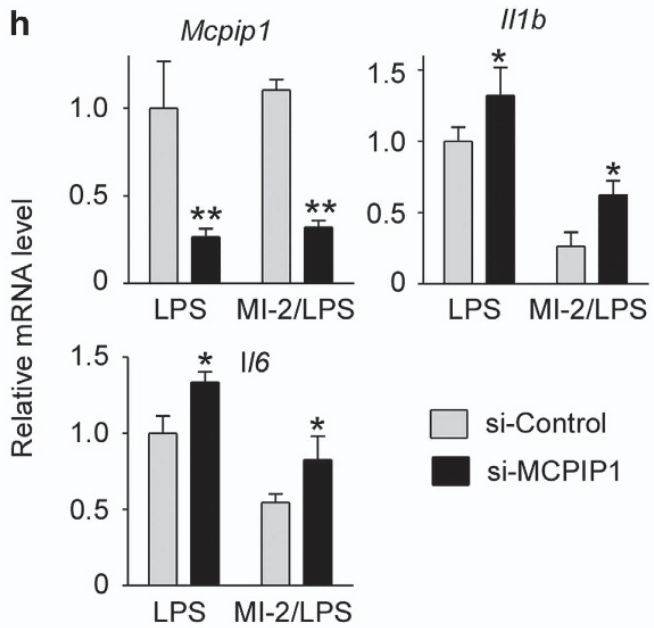

Figure 4. Pharmacological inhibition of MALT1 with MI-2 selectively increased the abundance of the MCPIP1 protein and suppressed LPSinduced macrophage activation. (a, b) Raw264.7 cells were treated with Ml-2 for different durations or doses as indicated. Cell lysates were subjected to analysis by immunoblot with the MCPIP1 antibody. $\beta$-actin served as a loading control. Fold changes of the MCPIP1 protein levels were determined by densitometry and normalized to $\beta$-actin. Data are representative of three independent experiments. (c) Raw264.7 were pretreated with or without $1 \mu \mathrm{M} \mathrm{Ml}-2$ for $1 \mathrm{~h}$ and then stimulated with or without $1 \mu \mathrm{g} / \mathrm{ml}$ LPS for $4 \mathrm{~h}$. The protein levels from different genes were determined by Western blot with individual antibodies as indicated. $\beta$-actin served as a loading control. (d) Fold-change of the MCPIP1 and C/EBPS protein levels were determined by densitometry and normalized to $\beta$-actin. Data are presented as the means \pm s.d. $(n=3$ ), ${ }^{*} P<0.05$ by Student's $t$-test. (e) Raw264.7 were pretreated with or without $1 \mu \mathrm{M}$ of Ml-2 for 30 min and then stimulated with or without $1 \mu \mathrm{g} /$ $\mathrm{ml}$ LPS for $4 \mathrm{~h}$. The mRNA levels of selected cytokines were determined by qPCR analysis and normalized to the $\beta$-actin mRNA levels. Data are presented as the means \pm s.d. $(n=4),{ }^{*} P<0.05$ by Student's $t$-test. (f) Raw264.7 cells were transfected with si-Control or si-MCPIP1 for $24 \mathrm{~h}$. The transfected cells were pretreated with or without $1 \mu \mathrm{M} \mathrm{Ml}-2$ for $1 \mathrm{~h}$ and then stimulated with or without $1 \mu \mathrm{g} / \mathrm{ml}$ of LPS for $4 \mathrm{~h}$. The protein levels of different genes were determined by immunoblot with specific antibodies. $\beta$-actin served as a loading control. (g) Fold-change of the MCPIP1 and C/EBPS protein levels were determined by densitometry and normalized to $\beta$-actin. Data are presented as the means \pm s.d. $(n=3$ ), ${ }^{*} P<0.05$ by Student's $t$-test. (h) Raw264.7 cells were transfected with si-Control or si-MCPIP1 for $24 \mathrm{~h}$. Transfected cells were pretreated with or without $1 \mu \mathrm{M} \mathrm{Ml}-2$ for $1 \mathrm{~h}$ and then stimulated with or without $1 \mu \mathrm{g} / \mathrm{ml}$ LPS for $4 \mathrm{~h}$. The mRNA levels of MCPIP1 and selected cytokines were determined by qPCR analysis and normalized to actin mRNA levels. Data are presented as the means \pm s.d. $(n=4),{ }^{*} P<0.05$ by Student's $t$-test. 
a

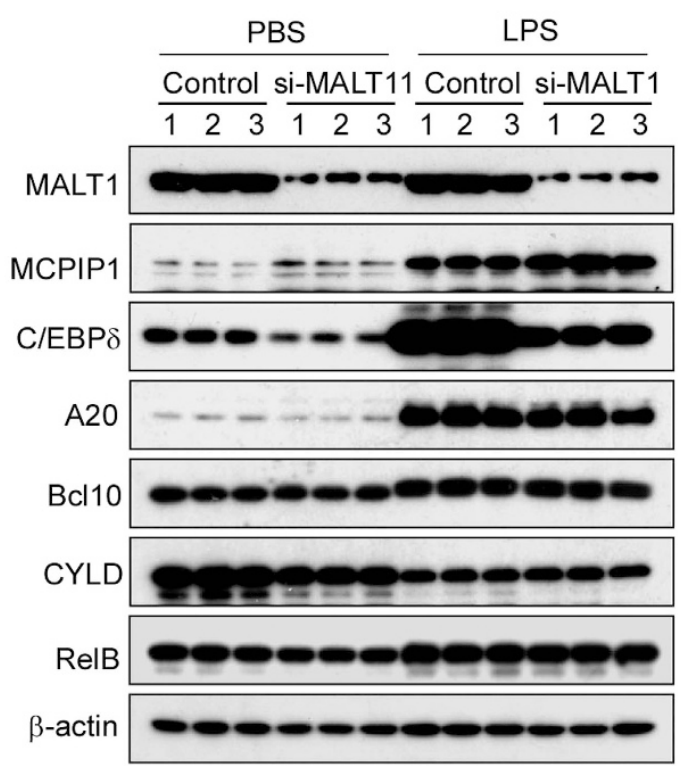

b

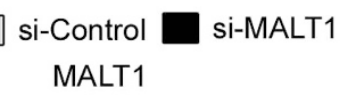

si-Control $\square$ si-MALT1 MALT1
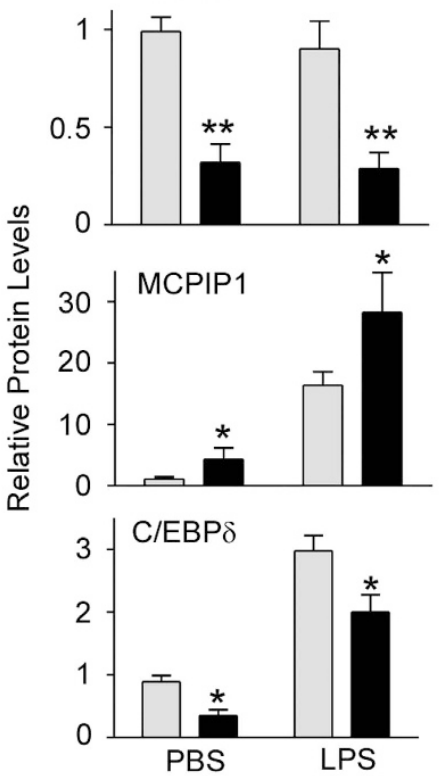

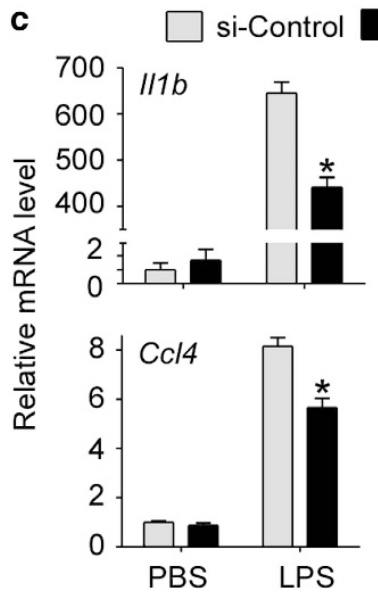

si-MALT1
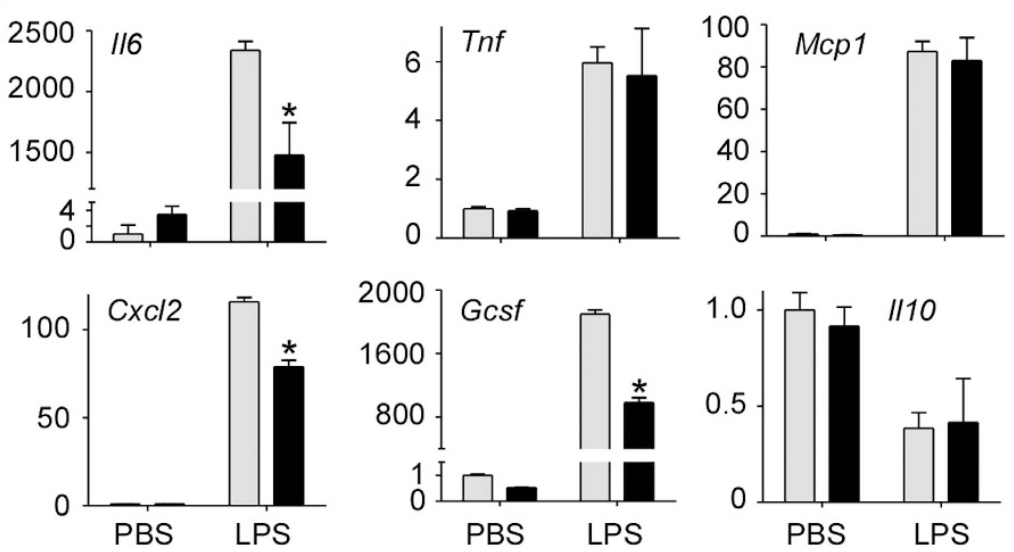

Figure 5. SiRNA-mediated knockdown of MALT1 selectively increased the abundance of the MCPIP1 protein and suppressed LPS-induced macrophage activation. (a) Raw264.7 cells were transfected with si-Control or si-MALT1 for $24 \mathrm{~h}$. Transfected cells were stimulated with or without $100 \mathrm{ng} / \mathrm{ml}$ LPS for $8 \mathrm{~h}$. The protein levels of different genes were determined by immunoblot with individual antibodies as indicated. $\beta$-actin served as a loading control. (b) Fold-change of the MCPIP1 and C/EBP $\delta$ protein levels were determined by densitometry and normalized to $\beta$-actin. Data are presented as the means \pm s.d. $(n=3),{ }^{*} P<0.05$ by Student's $t$-test. (c) Raw264.7 cells were transfected with siControl or si-MALT1 for $24 \mathrm{~h}$. Transfected cells were stimulated with or without $100 \mathrm{ng} / \mathrm{ml}$ LPS for $8 \mathrm{~h}$. The mRNA levels of MCPIP1 and cytokines as indicated were determined by qPCR analysis and normalized to actin mRNA levels. Data are presented as the means \pm s.d. $(n=4)$, ${ }^{*} P<0.05$ by Student's $t$-test.

MI-2 administration prevented LPS-induced MCPIP1 protein degradation in the lungs

As previously reported, MCPIP1 is subjected to phosphorylation and degradation at early time points during LPS and cytokineinduced macrophage activation. ${ }^{36}$ However, changes in the MCPIP1 protein levels in vivo during LPS-induced systemic inflammation and lung injury remain unknown. We examined the MCPIP1 protein levels in mouse lungs $0,2,4$ and $8 \mathrm{~h}$ after LPS injection ( $25 \mathrm{mg} / \mathrm{kg}$ body weight, i.p.) by immunoblot analysis. As shown in Figures $6 a$ and b, the MCPIP1 protein levels gradually decreased after LPS treatment and were essentially undetectable by $8 \mathrm{~h}$. The MALT1 protein levels were not changed by LPS administration, whereas the C/EBP $\delta$ and C/EBP $\beta$ protein levels were increased 2 and $4 \mathrm{~h}$ after LPS administration and remained elevated at $8 \mathrm{~h}$. To further verify that LPS-treatment promoted MCPIP1 protein degradation in the lungs, mice were injected with LPS $(25 \mathrm{mg} / \mathrm{kg}$ body weight, i.p.) and sacrificed after $8 \mathrm{~h}$. Immunoblot analysis showed that the MCPIP1 protein levels were markedly decreased in lungs from LPS-treated mice compared with those from control mice, whereas the C/EBP $\delta$ protein levels were significantly increased (Figures $6 c$ and $d$ ). These results suggest that LPS administration may induce degradation of MCPIP1 in vivo. To test whether administration of Ml-2 could prevent LPS-induced MCPIP1 protein degradation in vivo, mice were treated with or without Ml-2 (25 mg/body weight, i.p.) and then treated with or without LPS ( $25 \mathrm{mg} / \mathrm{kg}$ body weight, i.p.) $2 \mathrm{~h}$ later. Another group of mice was injected with LPS and then treated with MI- $2 \mathrm{~h}$ later. All mice were sacrificed $8 \mathrm{~h}$ after LPS 
a

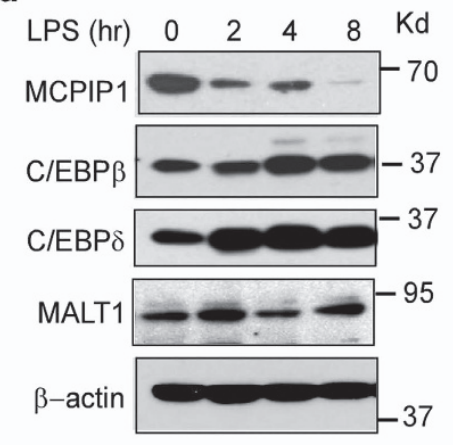

C

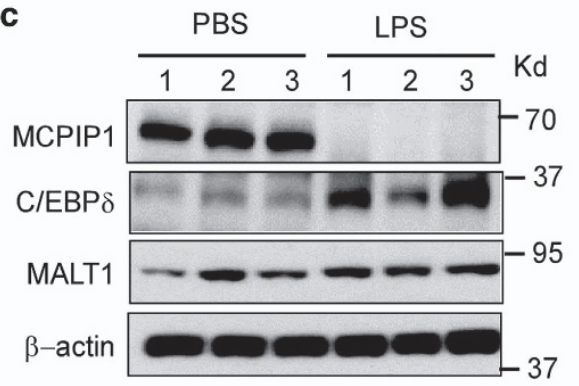

e

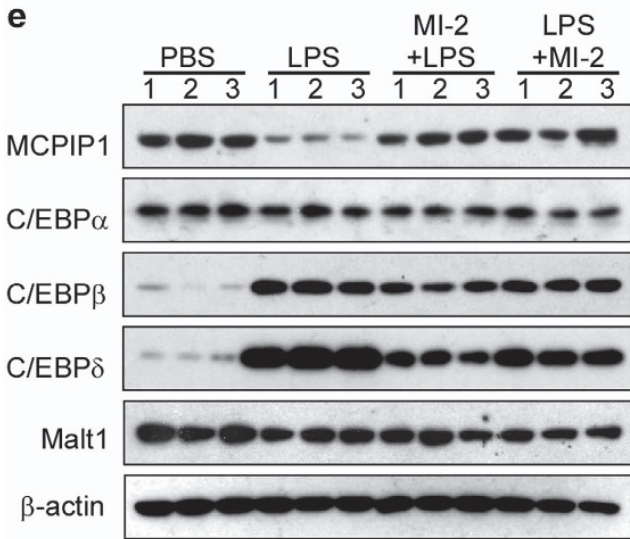

b
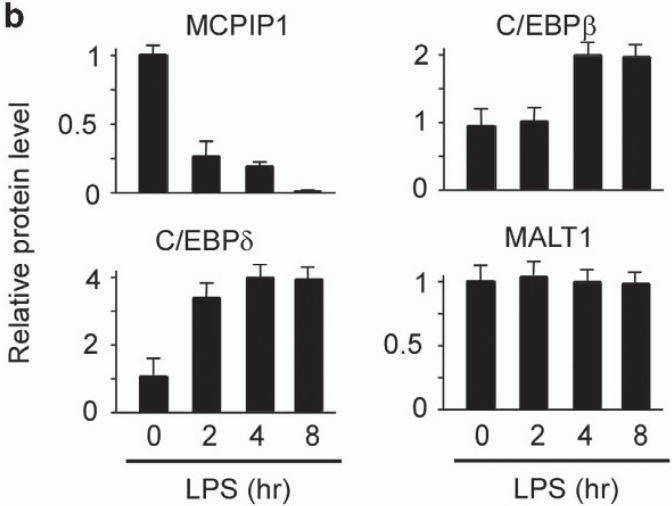

MALT1

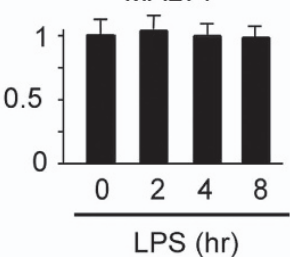

d
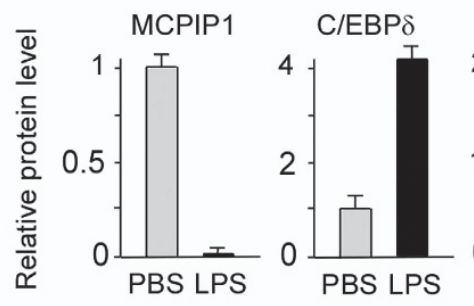

MALT1

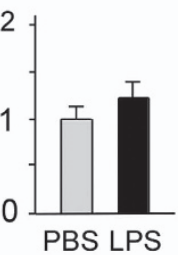

f

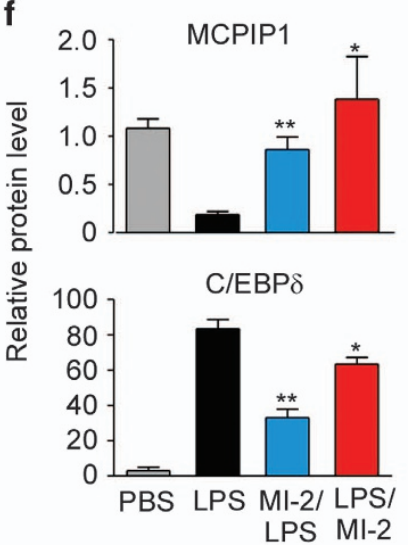

Figure 6. Administration of MI-2 prevented LPS-induced MCPIP1 protein degradation in vivo. (a) Adult C57BL/6 mice were intraperitoneally injected with LPS ( $25 \mathrm{mg} / \mathrm{kg}$ body weight) for different times as indicated. The mice were euthanized, and the lungs were collected for immunoblot analysis with different antibodies, as indicated. $\beta$-actin serves as a loading control. (b) Fold-change of the protein levels were determined by densitometry and normalized to $\beta$-actin. Data are presented as the means \pm s.d. $(n=3)$. (c) Adult C57BL/6 mice were intraperitoneally injected with LPS ( $25 \mathrm{mg} / \mathrm{kg}$ body weight) for $8 \mathrm{~h}$. Mice were euthanized, and the lungs were collected for immunoblot analysis with specific antibodies, as indicated. $\beta$-actin serves as a loading control. (d) Fold-changes of the protein levels were determined by densitometry and normalized to $\beta$-actin. Data are presented as the means \pm s.d. $(n=3)$. (e) Adult C57BL/6 mice were intraperitoneally injected with PBS or LPS $(25 \mathrm{mg} / \mathrm{kg}$ body weight) for $8 \mathrm{~h}$. One group of mice was pretreated with Ml- 2 for $2 \mathrm{~h}$ and then injected with LPS for $8 \mathrm{~h}$; the other group of mice was injected with LPS for $2 \mathrm{~h}$ and then treated with MI-2. Mice were euthanized $8 \mathrm{~h}$ after LPS injection. The lungs were collected for immunoblot analysis with specific antibodies as indicated. $\beta$-actin serves as a loading control. (f) Fold-changes of protein levels in (e) were determined by densitometry and normalized to $\beta$-actin. Data are presented as the means \pm s.d. $(n=3)$. ${ }^{*} P<0.05,{ }^{* *} P<0.01$ by Student's $t$-test.

injection, and the lungs were collected for immunoblot analysis. As shown in Figures 6e and $\mathrm{f}$, LPS induced MCPIP1 degradation in the lungs as expected. MI-2 treatment either before or after LPS injection prevented LPS-induced decreases in the MCPIP1 protein levels. While he MALT1 and C/EBPa protein levels were not changed by any of these treatments, the C/EBP $\beta$ and C/EBP $\delta$ protein levels were both increased by LPS and decreased by MI-2 treatment. Taken together, these results demonstrate that the MCPIP1 protein levels in the lungs are preserved by pharmacological inhibition of MALT1 protease, suggesting that MALT1 mediates LPS-induced degradation of MCPIP1 protein in the lungs. Furthermore, pharmacologic inhibition of MCPIP1 degradation with $\mathrm{Ml}-2$ results in increased levels of C/EBP $\beta$ and C/EBP $\delta$ proteins in the lungs.

Administration of Ml-2 protects mice from LPS-induced inflammation, lung injury and death

To test whether administration of Ml-2 protects mice from LPSinduced death, mice were divided into two groups: one group was injected solely with a lethal dose of LPS $(40 \mathrm{mg} / \mathrm{kg}$ body weight, i. 
p.); the other group was pre-treated with $\mathrm{Ml}-2$ ( $25 \mathrm{mg} / \mathrm{Kg}$ body weight, i.p.) $2 \mathrm{~h}$ before LPS injection and another dose at $2 \mathrm{~h}$ postLPS injection. All mice were closely monitored, and a 'moribund status' was equated to death to minimize the discomfort of the mice. The survival rate was recorded. As shown in Figure 7a, administration of Ml-2 significantly improved survival of mice
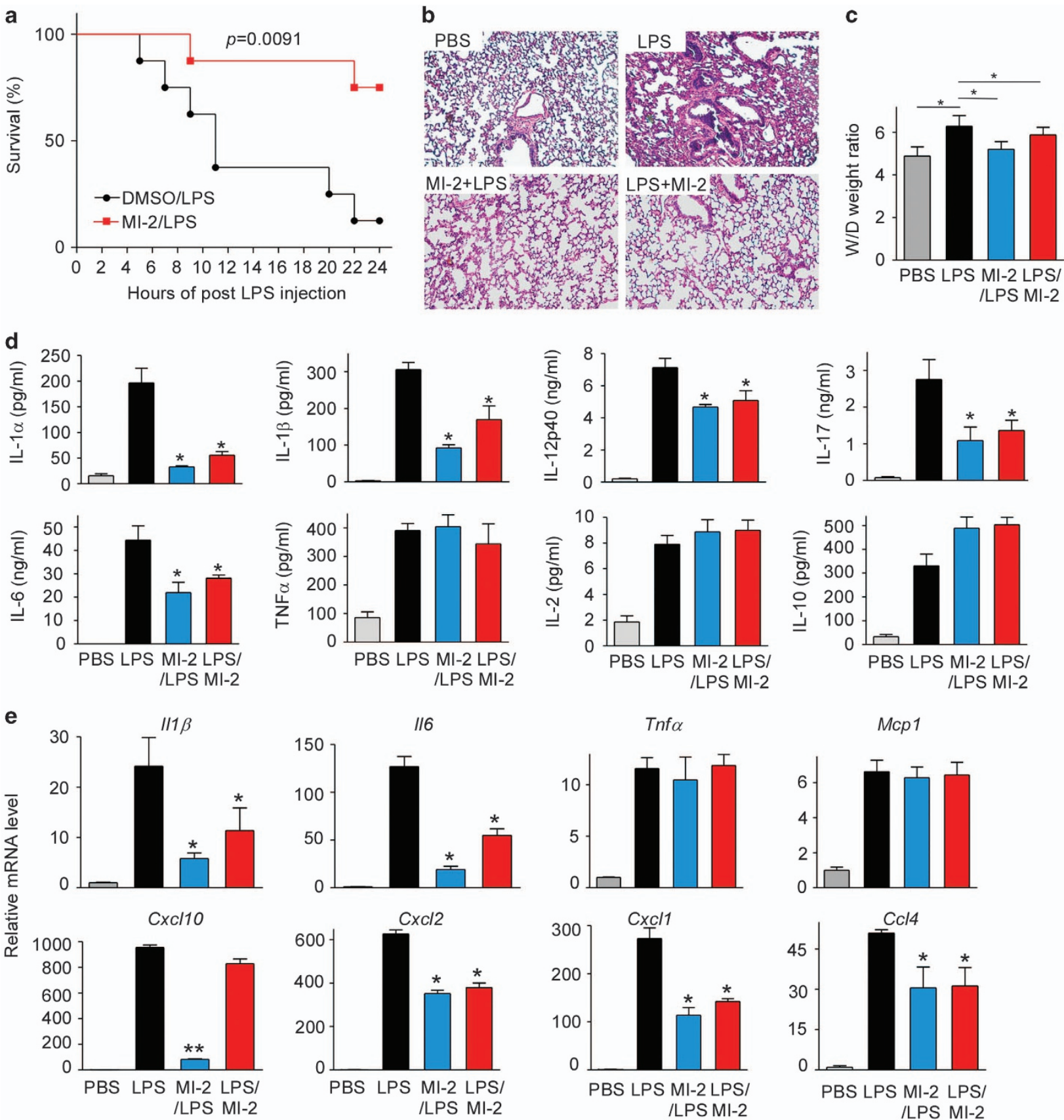

Figure 7. Administration of Ml-2 protected mice from LPS-induced inflammation, lung injury and death. (a) C57BL/6 mice from Jackson Laboratory were divided into two groups: one group was only injected with a lethal dose of LPS (40 mg/kg body weight, i.p.); the other group was pre-treated with Ml-2 (25 mg/Kg body weight, i.p.) at $2 \mathrm{~h}$ before LPS injection and another dose at $2 \mathrm{~h}$ post-LPS injection. All mice were closely monitored, and 'moribund status' was equated with death to minimize the discomfort of the mice. The survival rate was recorded. The data were analyzed by the log-rank Mantel-Cox test. $P=0.0091, N=8$. (b and d) Adult C57BL/6 mice were divided into four groups. Two groups of mice were intraperitoneally injected with PBS or LPS ( $25 \mathrm{mg} / \mathrm{kg}$ body weight) for $8 \mathrm{~h}$. The third group of mice was pretreated with MI-2 for $2 \mathrm{~h}$ and then injected with LPS for $8 \mathrm{~h}$; the fourth group of mice was injected with LPS for $2 \mathrm{~h}$ and then treated with MI-2. Mice were euthanized $8 \mathrm{~h}$ after LPS injection. Sera and lungs were collected for ELISA, H\&E staining or qPCR analysis. The serum cytokine levels were measured by ELISA (d), and lung sections were analyzed by H\&E staining (b). Data are presented as the means \pm s.d. ( $n=3$ ). ${ }^{*} P<0.05$ by Student's $t$-test. Data are representative of three independent experiments. (c) Changes of lung wet-to-dry weight ratios in mice. Data are presented as the means \pm s.d. $(n=3),{ }^{*} P<0.05$ by Student's $t$-test. (e) qPCR analysis of the mRNA levels for selected cytokines and chemokines in the lungs collected from the mice in (b). Data are representative of three independent experiments with 3 mice per group. ${ }^{*} P<0.05$ by Student's $t$-test. 
injected with LPS. To test whether administration of MI-2 protects mice from LPS-induced inflammation and lung injury, mice were divided into four groups as described in Figure 6e. All mice were sacrificed $8 \mathrm{~h}$ after LPS injection. Sera and lungs were collected for analysis by ELISA, histology and qPCR. LPS inoculation induced inflammatory cell infiltration and lung edema in the lungs, as expected (Figures $7 \mathrm{~b}$ and c). Intriguingly, Ml-2 treatment, either before or after LPS injection, significantly attenuated LPSinduced lung injury, as demonstrated by decreased inflammatory cell infiltrates and edema (Figures $7 \mathrm{~b}$ and $\mathrm{c}$ ). LPS inoculation induced significant increases in the serum concentrations of IL-1a, IL-1 $\beta$, IL-6, IL-12p40, TNFa, IL-17, IL-2 and IL-10. MI-2 treatment, either before or after LPS inoculation; significantly attenuated the response to LPS for IL-1a, IL-1 $\beta, \mathrm{IL}-6, \mathrm{IL}-12 \mathrm{p} 40$, and IL-17; but did not affect the production of TNFa, IL-2, and IL-10 (Figure 7d). Additional cytokine levels, such as for IL-2, IL-5, IL-9, II13 , MIP-1a, MIP-1 $\beta$, Eotaxin, and G-CSF, were not affected by MI-2 treatment, except that the level of IFNY was decreased by MI-2 treatment (Supplementary Figure S5). Finally, we measured the mRNA levels of inflammatory markers for macrophage activation in the lungs of these mice. As shown in Figure 7e, the mRNA levels of IL-1 $\beta, I L-6, T N F a, M C P 1, C X C L 10, C X C L 2, C X C L 1$, and CCL4 were increased by LPS injection. MI-2 treatment, either before or after LPS injection, attenuated LPS-induced mRNA expression of IL-1 $\beta, I L-6, C X C L 2, C X C L 1$, and CCL4. MI-2 treatment did not suppress LPS-induced expression of TNFa and MCP1 mRNA in the lungs and only suppressed the CXCL10 levels when it was given prior to LPS treatment. Taken together, these results suggest that pharmacological inhibition of MALT1 protease activity with MI-2 protects mice from LPS-induced inflammation, lung injury and death.

\section{DISCUSSION}

The major new findings of the current study were: 1) that MCPIP1 expression in myeloid cells plays a central role in protecting against LPS-induced inflammation, lung injury and death; 2) that decreases in the MCPIP1 levels in macrophages following LPS inoculation are attributable, at least in part, to increased proteolysis by MALT1; 3) that pharmacologic inhibition of MALT1 with Ml-2 protects against LPS-induced lung injury; 4) that both C/ EBP $\beta$ and C/EBP $\delta$ mRNAs are targets of MCPIP1 RNase; and 5) that the severe inflammatory syndrome that develops in mice with a global MCPIP1 deficiency is significantly delayed and has decreased severity in mice with a myeloid-specific MCPIP1 deficiency.

The conclusions stated above are based on the following experimental evidence. First, we demonstrated that inflammatory damage to the lungs and that the protein and mRNA levels of various proinflammatory cytokines were elevated in the serum and lungs, respectively, of LPS-treated myeloid-specific MCPIP1 knockout mice compared to LPS treated control mice. We also demonstrated that mRNA for IL-6, IL-1 $\beta$, C/EBP $\beta$ and C/ EBP $\delta$ and that the protein levels for C/EBP $\beta$ and C/EBP $\delta$ were higher in LPS-stimulated BMDM's from myeloid specific MCPIP1 knockout mice compared to BMDMs from LPS-treated control mice. Additionally, MCPIP1 overexpression in the Raw264.7 murine macrophage cell line resulted in suppressed mRNA levels for C/EBP $\beta$ and C/EBP $\delta$. Next, we demonstrated that the MCPIP1 protein levels in Raw264.7 cells were increased by treatment with MI-2, a specific inhibitor of MALT1 protease, in a time- and dose-dependent manner. Furthermore, MI-2 treatment of LPS-stimulated RAW264.7 cells enhanced the MCPIP1 protein levels and decreased the C/EBP $\delta$ protein and IL-1 $\beta$ and IL-6 mRNA levels. That the effects of MI-2-mediated inhibition of MALT1 were mediated through MCPIP1 and were confirmed by demonstrating that MCPIP1 siRNA reversed the effects of MI-2 treatment. We also demonstrated that treatment of macrophages with MALT1 siRNA consistently enhanced the MCPIP1 protein levels and decreased expression of IL-1 $\beta$ and IL-6 mRNAs as well as the C/EBPS protein. Finally, we demonstrated that MI-2 treatment increased the MCPIP1 protein levels in the lungs as well as decreased inflammatory infiltrates and the C/EBP $\beta$ and C/EBP $\delta$ protein levels, along with protein and mRNA for several other proinflammatory cytokines, in the lungs of LPS-injected mice. These collective findings support the conclusions that myeloid MCPIP1 suppresses production of C/ $\mathrm{EBP} \beta, \mathrm{C} / \mathrm{EBP} \delta$, and a variety of proinflammatory cytokines through its RNase activity and that pharmacologic inhibition of MALT1 protease enhances the MCPIP1 protein levels, thereby suppressing LPS-induced inflammatory responses. The rationale for assessing C/EBP $\beta$ and C/EBP $\delta$ rather other transcriptional factors in M-Mcpip 1 ${ }^{-/-}$BMDMs is that C/EBP $\beta$ and C/EBP $\delta$ have been reported to be the major transcriptional drivers of the inflammation and lung injury, and many cytokine expression level changes are not due to their mRNA decay. We therefore evaluated whether MCPIP1 RNAse affects those cytokine expression levels by targeting major transcription factors, such as C/EBP $\beta$ and C/EBP $\delta$. During the preparation of this manuscript, another group independently identified C/EBP $\beta$ as a new target of MCPIP1 RNase. Our results further confirm it as target of MCPIP1 in macrophages.

We also found that a myeloid-specific deficiency of MCPIP1 resulted in no overt phenotypic changes in mice during the first several months of life, in contrast to the early-onset, severe inflammatory syndrome characteristic of the total MCPIP1 deficiency. ${ }^{22-24}$ This suggests that a MCPIP1 deficiency in cell types other than macrophages is also required for the development of the severe inflammatory syndrome phenotype in this strain of mice. It has previously been reported that mice with a T cell-specific MCPIP1 deficiency develop an inflammatory syndrome within 3 months of life, ${ }^{30}$ suggesting that MCPIP1 is indispensable for controlling the activation of both innate and adaptive immune cells. ${ }^{30}$ After 5 months of age, M-Mcpip1 ${ }^{-1-}$ mice gradually developed an inflammatory syndrome characterized by splenomegaly, lymphadenopathy, and multi-organ inflammation, which is similar to the phenotypes described for MCPIP1 global knockout mice. ${ }^{22-24}$ The underlying mechanisms by which the myeloid-specific MCPIP1 deficiency contributes to abnormal responses in both innate and adaptive immune systems warrants further investigation.

The extreme sensitivity of M-MCPIP1 KO mice to LPS-induced inflammation and lung injury appears to be attributable, at least in part, to the high serum concentrations of proinflammatory cytokines and chemokines that develop after LPS injection. These, in turn, could be attributed to the high production of inflammatory cytokines by macrophages and other myeloid cells. Expression profiling of inflammatory cytokines in BMDMS showed that many proinflammatory cytokines and chemokines, including MCPIP1 RNase targets and non-targets, were significantly increased in MCPIP1-deficient macrophages. We further identified both C/EBP $\beta$ and C/EBP $\delta$ mRNAs as targets of MCPIP1 RNase. As C/ EBP $\beta$ and C/EBP $\delta$ are critical transcription factors that drive the expression of a plethora of inflammatory genes and critically contribute to lung inflammatory injuries, ${ }^{37-40}$ enhanced expression of C/EBP $\beta$ and C/EBP $\delta$ in MCPIP1-deficient macrophages is likely to contribute to the phenotypes observed in M-MCPIP1 KO mice.

In our studies, although MCPIP1 affects both the C/EBP $\beta$ and C/ EBP $\beta$ mRNA expression levels in BMDMs, Ml-2 treatment predominantly affects C/EBP $\delta$ in macrophages and the lungs, suggesting that the C/EBP $\delta$ changes are more robust in Mcpip1deficient tissues and cells. Indeed, in the transcriptional program of inflammation, C/EBPS plays a more important role than C/ EBP ${ }^{28}{ }^{28}$ In addition, the effects of MI-2 on the protein levels of MCPIP1 or C/EBPS were more dramatic with LPS treatment. LPS 

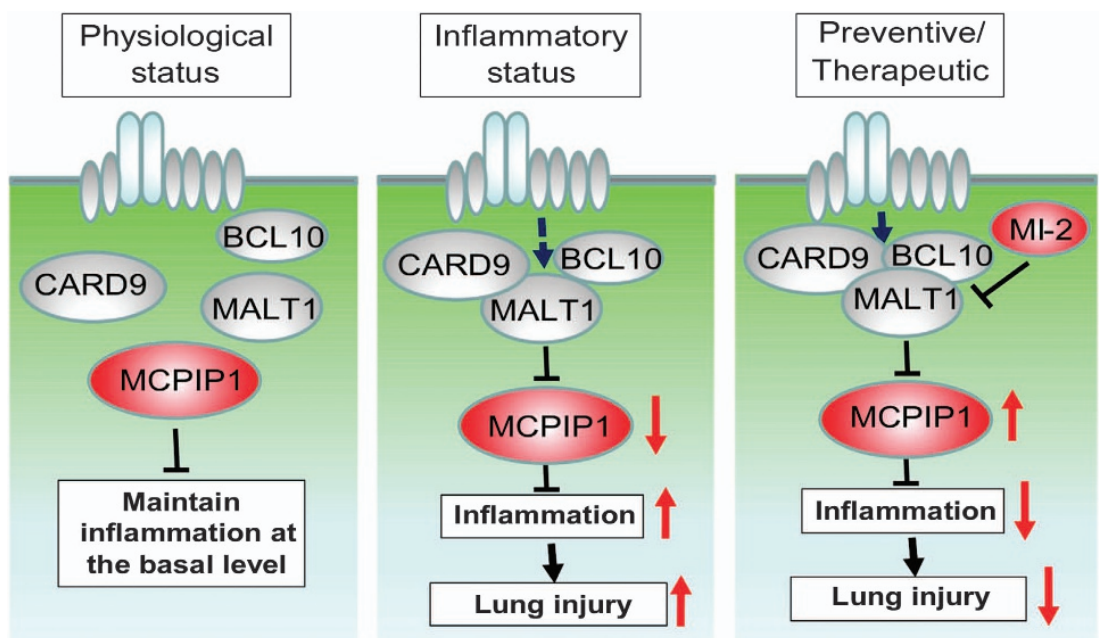

Figure 8. Schematic representation of the central role of MCPIP1 in LPS-induced inflammation and lung injury. As an RNase, MCPIP1 posttranscriptionally controls the production of cytokines and maintains inflammation at a basal level under physiological conditions. In response to inflammatory stimuli (for example, LPS), macrophage CARD9/BCL10/MALT1 signalosome is activated and MALT1 protease mediates MCPIP1 cleavage, which releases the 'brake' and initiates the inflammatory response. MI-2 specifically inhibits MALT1 protease activity and preserves the MCPIP1 protein levels, which can prevent/treat LPS-induced inflammation and lung injury.

stimulation activates the MALT1/BCL10/CARD9 complex and degrades MCPIP1 protein, which may be why the effect of MI-2 is more dramatic with LPS treatment.

Protein degradation of MCPIP1 in activated T cells has been attributed to the protease activity of MALT1, ${ }^{30}$ which is a main component of the signalosome complex CARD11/BCL10/ MALT1. ${ }^{41-43}$ In addition to MCPIP1, MALT1 protease also cleaves several other targets, including A20, CYLD, BCL10 and RelB, in lymphocytes. ${ }^{31-34}$ Dong et al. reported that the BCL10/MALT1 complex also mediated NF-KB activation in macrophages in response to TLR activation; ${ }^{44}$ however, whether MCPIP1 protein is subjected to cleavage by MALT1 in macrophages has not been previously reported. In the present study, we observed that MI-2, a specific inhibitor of MALT1 protease, markedly increased the MCPIP1 protein levels in both resting and activated macrophages, suggesting that MALT1 protease activity controls the MCPIP1 protein levels under basal and stimulated conditions. Interestingly, other targets of MALT1 identified in lymphocytes, including A20, CYLD, BCL10 and RelB, were not affected in resting or activated macrophages by $\mathrm{Ml}-2$ treatment. To further confirm that MALT1 protease-mediated the cleavage of MCPIP1 in macrophages, we used siRNA to knockdown MALT1 expression in macrophages, confirming that MALT1 promoted MCPIP1, but not A20, CYLD, BCL10 or RelB, degradation. The mechanism by which MALT1 protease selectively cleaves MCPIP1 in macrophages, but not other protein targets identified in lymphocytes, remains to be determined. In addition, Iwaski et al. reported that LPS induces degradation of MCPIP1 in vitro at very early time points. ${ }^{36}$ In our experiments, LPS degraded MCPIP 1 in the lungs at $2 \mathrm{~h}$ after LPS challenge. We believe that the time course of MCPIP1 degradation in vivo and in vitro is different. However, we cannot exclude the possibility that other cells in addition to macrophages may also be involved in this process.

Our findings that $\mathrm{Ml}-2$ administration prevents MALT1mediated MCPIP1 degradation in vivo and protects mice from LPS-induced inflammation and lung injury, suggests that pharmacological inhibition of MALT1 protease activity by Ml-2 may be an effective strategy for preventing/treating sepsisassociated lung injury. It is particularly relevant that Ml-2 is not toxic in mice even after prolonged exposure. ${ }^{31}$ Several reports have demonstrated that Ml-2 is effective for the prevention/ treatment of activated B cell-like diffuse large B cell lymphoma (ABC-DLBCL), HIV and experimental colitis. ${ }^{31,45,46}$ However, several recent studies have shown that mice expressing catalytically inactive MALT1 develop multi-organ inflammation and autoimmunity. ${ }^{47-50}$ The mechanism underlying these results appears to be that MALT1 protease activity is required for the development of Treg cells; disruption of MALT1 protease activity leads to deficient Treg development as well as excessive inflammation and autoimmunity. ${ }^{47-50}$ In our experiments, shortterm treatment with $\mathrm{Ml}-2$ did not affect expression of IL-10, suggesting that such treatment does not affect Treg differentiation and function. However, further investigation is still required. Furthermore, in light of the essential role of MALT1 in inflammatory cell activation, inhibition of MALT1 protease activity may potentially lead to immune suppression and increased susceptibility to infections, which is another potential problem requiring additional exploration.

Degradation of MCPIP1 occurs through multiple mechanisms in addition to MALT1, such as proteasome-dependent degradation. Indeed, two groups have reported that MG132, an inhibitor of the proteasome, can enhance the MCPIP1 protein levels in vascular smooth muscle cells and skin cells. ${ }^{51,52}$ As the proteasome broadly targets protein degradation, MALT1 inhibitors have significant potential for the treatment of inflammation.

In summary, the present study is the first to identify the central role of myeloid MCPIP1 in protecting against LPSinduced inflammation, lung injury and death. MCPIP1 is an RNase that contributes to post-transcriptional control of inflammatory cytokine production and helps maintain inflammation at basal levels under physiological conditions. ${ }^{14}$ In response to inflammatory stimuli, the macrophage CARD9/ BCL10/MALT1 signalosome is activated and MALT1 protease cleaves MCPIP1, releasing the 'brake' that suppresses inflammation and initiating the inflammatory response. MI-2 specifically inhibits MALT1 protease activity and preserves MCPIP1 protein levels, which can prevent/treat LPS-induced inflammation and lung injury (Figure 8). 


\section{ACKNOWLEDGEMENTS}

We are grateful to Dr Esta Sterneck for providing pcDNA3.human C/EBPS 3'UTR. This work was supported by National Institutes of Health Grants (Al105618 to MF, HL11626 to DF) and a University of Missouri Research Board Grant (to MF).

\section{AUTHOR CONTRIBUTIONS}

$\mathrm{YL}, \mathrm{XH}, \mathrm{SH}$ and $\mathrm{MF}$ performed the experiments and analyzed data; $\mathrm{HH}$ performed genotyping; TL and YL performed histological H\&E staining and IHC analysis; FS and DF performed ELISA; AM provided the key reagents; XY and AK provided consults; MF designed and supervised the experiments; MF and CJP wrote the manuscript.

\section{COMPETING INTERESTS}

The authors declare no conflict of interest.

\section{REFERENCES}

1 de Montmollin E, Annane D. Year in review 2010: Critical Care--Multiple organ dysfunction and sepsis. Crit Care 2011; 15: 236.

2 Dushianthan A, Grocott MP, Postle AD, Cusack R. Acute respiratory distress syndrome and acute lung injury. Postgrad Med J 2011; 87: 612-622.

3 Matthay MA, Zemans RL. The acute respiratory distress syndrome: pathogenesis and treatment. Annu Rev Pathol 2011; 6: 147-163.

4 Cribbs SK, Martin GS. Stem cells in sepsis and acute lung injury. Am J Med Sci 2011; 341: 325-332.

5 López-Bojórquez LN, Dehesa AZ, Reyes-Terán G. Molecular mechanisms involved in the pathogenesis of septic shock. Arch Med Res 2004; 35: 465-479.

6 Saguil A, Fargo M. Acute respiratory distress syndrome: diagnosis and management. Am Fam Physician 2012; 85: 352-358.

7 Sadowitz B, Roy S, Gatto LA, Habashi N, Nieman G. Lung injury induced by sepsis: lessons learned from large animal models and future directions for treatment. Expert Rev Anti Infect Ther 2011; 9: 1169-1178.

8 Budinger GR, Walley KR. Predicting mortality in patients with acute lung injury. Am J Respir Crit Care Med 2011; 184: 394-395.

9 Sprague AH, Khalil RA. Inflammatory cytokines in vascular dysfunction and vascular disease. Biochem Pharmacol 2009; 78: 539-552.

10 Kracht $M$, Saklatvala J. Transcriptional and post-transcriptional control of gene expression in inflammation. Cytokine 2002; 20: 91-106.

11 Barnes PJ, Karin M. Nuclear factor- $\mathrm{KB}$ - a pivotal transcription factor in chronic inflammatory diseases. N Engl J Med 1997; 336: 1066-1071.

12 Litvak V, Ramsey SA, Rust AG, Zak DE, Kennedy KA, Lampano AE et al. Function of C/EBP $\delta$ in a regulatory circuit that discriminates between transient and persistent TLR4-induced signals. Nat Immunol 2009; 10: 437-433.

13 Liang J, Wang J, Azfer A, Song W, Tromp G, Kolattukudy PE et al. A novel CCCHZinc finger protein family regulates proinflammatory activation of macrophages. J Biol Chem 2008; 283: 6337-6346.

14 Fu M, Blackshear PJ. RNA-binding proteins in immune regulation: a focus on $\mathrm{CCCH}$ zinc finger proteins. Nat Rev Immunol 2017; 17: 130-143.

15 Huang S, Miao R, Zhou Z, Wang T, Liu J, Liu G et al. MCPIP1 negatively regulates toll-like receptor 4 signaling and protects mice from LPS-induced septic shock. Cell Signal 2013; 25: 1228-1234.

16 Zhou Z, Miao R, Huang S, Elder B, Quinn T, Papasian CJ et al. MCPIP1 deficiency in mice results in severe anemia related to autoimmune mechanisms. PLoS One 2013; 8: e82542.

17 Mino T, Murakawa Y, Fukao A, Vandenbon A, Wessels HH, Ori D et al. Regnase-1 and Roquin Regulate a Common Element in Inflammatory mRNAs by Spatiotemporally Distinct Mechanisms. Cell 2015; 161: 1058-1073.

18 Uehata T, Akira S. mRNA degradation by the endoribonuclease Regnase-1/ ZC3H12a/MCPIP-1. Biochim Biophys Acta 2013; 1829: 708-713.

19 Jura J, Skalniak L, Koj A. Monocyte chemotactic protein-1-induced protein-1 (MCPIP1) is a novel multifunctional modulator of inflammatory reactions. Biochim Biophys Acta 2012; 1823: 1905-1913.

20 Jeltsch KM, Hu D, Brenner S, Zöller J, Heinz GA, Nagel D, Vogel KU et al. MALT1 cleavage of roquin and regnase- 1 releases cooperatively repressed mRNA targets to promote TH17 differentiation. Nat Immunol 2014; 15: 1079-1089.

21 Mizgalska D, Wegrzyn P, Murzyn K, JeKasza A, Koj A, Jura J et al. Interleukin-1inducible MCPIP protein has structural and functional properties of RNase and participates in degradation of IL-1 beta mRNA. FEBS J 2009; 276: 7386-7399.

22 Matsushita K, Takeuchi O, Standley DM, Kumagai Y, Kawagoe T, Miyake T et al. Zc3h12a is an RNase essential for controlling immune responses by regulating mRNA decay. Nature 2009; 458: 1185-1190.
23 Liang J, Sadd Y, Lei T, Wang J, Qi D, Yang Q et al. MCP-induced protein 1 deubiquitinates TRAF proteins and negatively regulates JNK and NF-kappaB signaling. J Exp Med 2010; 207: 2959-2973.

24 Miao R, Huang S, Zhou Z, Quinn T, Van Treack B, Nayyar T et al. Targeted disruption of MCPIP1/Zc3h12a results in fatal inflammatory disease. Immunol Cell Biol 2013; 91: 368-376.

25 Clausen BE, Burkhardt C, Reith W, Renkawitz R, Forster I. Conditional gene targeting in macrophages and granulocytes using LysMcre mice. Transgenic Res 1999; 8: 265-277.

26 Grommes J, Soehnlein O. Contribution of neutrophils to acute lung injury. Mol Med 2011; 17: 293-307.

27 Lipert B, Wilamowski M, Gorecki A, Jura J. MCPIP1, alias Regnase-1 binds and cleaves mRNA of C/EBP 3 . PLoS One 2017; 12: e0174381.

28 Poli V. The role of C/EBP isoforms in the control of inflammatory and native immunity functions. J Biol Chem 1998; 273: 29279-29282.

29 Gorgoni B, Maritano D, Marthyn P, Righi M, Poli V. C/EBP beta gene inactivation causes both impaired and enhanced gene expression and inverse regulation of IL-12 p40 and p35 mRNAs in macrophages. J Immunol 2002; 168: 4055-4062.

30 Uehata T, Iwasaki H, Vandenbon A, Matsushita K, Hernandez-Cuellar E, Kuniyoshi $\mathrm{K}$ et al. Malt1-induced cleavage of regnase- 1 in $\mathrm{CD} 4(+)$ helper $\mathrm{T}$ cells regulates immune activation. Cell 2013; 153: 1036-1049.

31 Fontan L, Yang C, Kabaleeswaran V, Volpon L, Osborne MJ, Beltran E et al. MALT1 small molecule inhibitors specifically suppress $A B C-D L B C L$ in vitro and in vivo. Cancer Cell 2012; 22: 812-824.

32 Staal J, Driege Y, Bekaert T, Demeyer A, Muyllaert D, Van Damme P et al. T-cell receptor-induced JNK activation requires proteolytic inactivation of CYLD by MALT1. EMBO J 2011; 30: 1742-1752.

33 Coornaert B, Baens M, Heyninck K, Bekaert T, Haegman M, Staal J et al. T cell antigen receptor stimulation induces MALT1 paracaspase-mediated cleavage of the NF-kappaB inhibitor A20. Nat Immunol 2008; 9: 263-271.

34 Rebeaud F, Hailfinger S, Posevitz-Fejfar A, Tapernoux M, Moser R, Rueda D et al. The proteolytic activity of the paracaspase MALT1 is key in T cell activation. Nat Immunol 2008; 9: 272-281.

35 Hailfinger S, Nogai H, Pelzer C, Jaworski M, Cabalzar K, Charton JE et al. Malt1dependent RelB cleavage promotes canonical NF-kappaB activation in lymphocytes and lymphoma cell lines. Proc Natl Acad Sci USA 2011; 108: 14596-14601.

36 Iwasaki $\mathrm{H}$, Takeuchi O, Teraguchi S, Matsushita K, Uehata T, Kuniyoshi K et al. The IKB kinase complex regulates the stability of cytokine-encoding mRNA induced by TLR-IL-1R by controlling degradation of regnase-1. Nat Immunol 2011; 12: 1167-1175.

37 Yan C, Ward PA, Wang X, Gao H. Myeloid depletion of SOCS3 enhances LPSinduced acute lung injury through CCAAT/enhancer binding protein $\delta$ pathway. FASEB J 2013; 27: 2967-2976.

38 Yan C, Johnson PF, Tang H, Ye Y, Wu M, Gao H et al. CCAAT/enhancer-binding protein $\delta$ is a critical mediator of lipopolysaccharide-induced acute lung injury. Am J Pathol 2013; 182: 420-430.

39 Yan C, Wu M, Cao J, Tang H, Zhu M, Johnson PF et al. Critical role for CCAAT/ enhancer-binding protein $\beta$ in immune complex-induced acute lung injury. J Immunol 2012; 189: 1480-1490.

40 Do-Umehara HC, Chen C, Urich D, Zhou L, Qiu J, Jang S et al. Suppression of inflammation and acute lung injury by Miz1 via repression of C/EBP- $\delta$. Nat Immunol 2013; 14: 461-469.

41 Thome M. Multifunctional roles for MALT1 in T-cell activation. Nat Rev Immunol 2008; 8: 495-500.

42 Delekta PC, Apel IJ, Gu S, Siu K, Hattori Y, McAllister-Lucas LM et al. Thrombindependent NF-\{kappa\}B activation and monocyte/endothelial adhesion are mediated by the CARMA3.BCl10.MALT1 signalosome. J Biol Chem 2010; 285: 41432-41442.

43 Klei LR, Hu D, Panek R, Alfano DN, Bridwell RE, Bailey KM et al. MALT1 Protease Activation Triggers Acute Disruption of Endothelial Barrier Integrity via CYLD Cleavage. Cell Rep 2016; 17: 221-232.

44 Dong W, Liu Y, Peng J, Chen L, Zou T, Xiao H et al. The IRAK-1-BCL10-MALT1TRAF6-TAK1 cascade mediates signaling to NF-kappaB from Toll-like receptor 4. J Biol Chem 2006; 281: 26029-26040.

$45 \mathrm{Li} \mathrm{H}, \mathrm{He} \mathrm{H}$, Gong L, Fu M, Wang TT. Short Communication: Preferential Killing of HIV Latently Infected CD4(+) T Cells by MALT1 Inhibitor. AIDS Res Hum Retroviruses 2016; 32: 174-177.

46 Liu W, Guo W, Hang N, Yang Y, Wu X, Shen Y et al. MALT1 inhibitors prevent the development of DSS-induced experimental colitis in mice via inhibiting NF-KB and NLRP3 inflammasome activation. Oncotarget 2016; 7: 30536-30549.

47 Bornancin F, Renner F, Touil R, Sic H, Kolb Y, Touil-Allaoui I et al. Deficiency of MALT1 paracaspase activity results in unbalanced regulatory and effector $T$ and $B$ 
MCPIP1-mediated protection of lung injury

Y Li et al

cell responses leading to multiorgan inflammation. J Immunol 2015; 194: 3723-3734.

48 Gewies A, Gorka O, Bergmann H, Pechloff K, Petermann F, Jeltsch KM et al. Uncoupling Malt1 threshold function from paracaspase activity results in destructive autoimmune inflammation. Cell Rep 2014; 9: 1292-1305.

49 Yu JW, Hoffman S, Beal AM, Dykon A, Ringenberg MA, Hughes AC et al. MALT1 protease activity is required for innate and adaptive immune responses. PLoS One 2015; 10: e0127083.

50 Jaworski M, Marsland BJ, Gehrig J, Held W, Favre S, Luther SA et al. Malt1 protease inactivation efficiently dampens immune responses but causes spontaneous autoimmunity. EMBO J 2014; 33: 2765-2781.

51 Tan X, Gao J, Shi Z, Tai S, Chan LL, Yang Y et al. MG132 Induces Expression of Monocyte Chemotactic Protein-Induced Protein 1 in Vascular Smooth Muscle Cells. J Cell Physiol 2017; 232: 122-128.
52 Skalniak L, Koj A, Jura J. Proteasome inhibitor MG-132 induces MCPIP1 expression. FEBS J 2013; 280: 2665-2674.

(c) (i) This work is licensed under a Creative Commons Attribution 4.0 International License. The images or other third party material in this article are included in the article's Creative Commons license, unless indicated otherwise in the credit line; if the material is not included under the Creative Commons license, users will need to obtain permission from the license holder to reproduce the material. To view a copy of this license, visit http://creativecommons.org/licenses/ by/4.0/

(c) The Author(s) 2017

Supplementary Information accompanies the paper on the Signal Transduction and Targeted Therapy website (http://www.nature.com/sigtrans) 